\title{
1 Characterisation of porous anodic alumina membranes for ultrafiltration of protein nanoparticles as a size mimic of virus particles
}

3

4

5

6

7

8

9

10

11

12

13

14

15

Anshul Sharma a, Daniel G. Bracewell a*

a Department of Biochemical Engineering, Gower Street, University College London, UK WC1E 6BT

${ }^{*}$ Corresponding author (Email: $\underline{\text { d.bracewell@ucl.ac.uk) }}$

Declarations of Interest: none

\section{Keywords}

Ultrafiltration, viral vectors, protein nanoparticles, porous anodic alumina, membranes;

\section{Abstract}

Viral vectors used in emerging gene therapies face challenges of significant yield loss during downstream processing primarily due to their large size, fragility and mass transfer limitations of the traditional porous chromatography adsorbents. The large size of the vectors in relation to key impurities makes them suitable solutes for ultrafiltration-based separations. Efforts to utilise ultrafiltration for virus purification are often restricted to commercial polymeric membranes with wide pore size distributions and tortuous, interconnected channels. Membranes with narrow pore distributions and straight pore channels such as porous anodic alumina (PAA) may present opportunities for improved virus purification. This paper examines the use of porous anodic alumina membranes for application in virus separation by using model solutes such as thyroglobulin and protein nanoparticles. A systematic approach is used to select a polymeric ultrafiltration membrane rating for comparison with $20 \mathrm{~nm}$ rated PAA membrane by comparing hydraulic permeability and dextran sieving characteristics of the membranes. Differences in the filterability of the model solutes were characterised. Finally, a discontinuous diafiltration experiment was employed to fractionate smaller model impurity and protein nanoparticles. Results indicate that PAA membranes have superior fouling resistance with 3-4 folds higher flux recovery ratio and 3-fold higher purification factors compared to the polymeric membranes, but the presence of surface defects make them more susceptible to product loss through leaky transmission.

\section{Introduction}

Emerging therapies such as gene therapy and cell therapies employ viral vectors for vaccine and therapeutic uses. Biomanufacturing of the viral vectors at present suffers from low process yields due to suboptimal chromatography processes due to inaccessibility of the resin pores for large solutes such as viral vectors resulting in an order of magnitude lower binding capacities compared to proteins [1]. New materials with a more open porous architecture such as gigaporous resins [2], monoliths [3, 4] and nanofiber adsorbers [5] are being actively looked into. Limited studies have been carried out to explore the use of ultrafiltration based processing instead of chromatography based processes by 
exploiting differences in the size of impurities and viral particles [6-9]. Most of the reported literature compares different molecular weight rating or pore size ratings of polymeric ultrafiltration membranes or different modules such as hollow fibre and cassette $[6,8]$. These membranes have wide pore size distribution, which is often reported to affect the membrane performance especially retention of large biomolecules such as viruses [10,11]. Isoporous membranes with different porous architectures such as porous anodic alumina (PAA) membranes are however being investigated in other fields such as nanofiltration for water purification and biosensors.

Porous anodic alumina membranes are widely studied for applications in label-free biosensors [12-14] for use as point-of-care diagnostic devices. Applications of PAA membranes in bioseparations have been limited to diffusion based separations for haemodialysis [15], separation of similarly sized proteins by exploiting differences in solute charge [16], enriching phosphoproteins for mass spectrometry [17] and ultrafiltration of small proteins [18-20]. A few reports on PAA membranes have examined their potential for virus separations. Moon et al., [21] reported the ability of 35-nm pores of a PAA membrane to separate empty and genome filled virus particles of a bacteriophage in centrifugal filtration. Jeon et al., [22] have described the use of a PAA membrane for enrichment of hepatitis $C$ viruses and when compared to ultracentrifugation achieved four times higher recovery. These studies, however, did not compare the PAA membranes to conventionally used polymeric membranes and also did not study filtration performance such as flux decline and fouling of the membranes. Further, most of the studies have used custom fabricated membranes and not the commercially available membranes. This work evaluates a commercial PAA membrane for filtration and separation performance and compares them with a traditional polymeric membrane for potential applications in virus ultrafiltration.

Working with live virus feeds can be challenging due to laborious, time and resource consuming cell culture-based production and subsequent recovery of labile virus particles, the requirement for biosafety containment for all of the experiments and sophisticated analytical tools required such as infectivity and immunochemical assays. Nano-particulates such as inclusion bodies [23] and synthesised protein nanoparticles [24] have been previously used in purification studies as surrogates for virus particles. In this article, we report on the use of model solutes such as large proteins and protein nanoparticles as mimics for viral vectors in ultrafiltration studies. Monodisperse bovine serum albumin nanoparticles (BSA NP) preparations were prepared as reported in the literature [25]. This paper presents a systematic approach for the selection of pore ratings for porous anodic alumina and polymeric membranes to compare these two membrane types of radically different architecture for filterability of large biomolecules. BSA NP of $80-90 \mathrm{~nm}$ diameter and thyroglobulin of $20 \mathrm{~nm}$ diameters are used as physical mimics for viral vectors representing larger adenovirus and smaller vectors, such as adeno-associated virus respectively. Bovine serum albumin of $66 \mathrm{kDa}$ is used as a model impurity given that most of the host cell proteins in mammalian cell cultures are in the range of 50-100 kDa in molecular weight [26] and albumin is also the most abundant protein in the serum supplemented growth media used in mammalian cell culture. Membrane fouling by these large solutes is studied, and mechanisms of fouling are identified using a statistical curve fitting of experimental data with 
established mathematical models [27]. Separation performance of the membranes was also compared using mixtures of the model solutes and impurity (BSA) and performing an ultrafiltrationdiafiltration (UF/DF) run to aid in the fractionation. A hypothesis is put forward to explain the differences observed in fouling and sieving behaviour of the two membranes on the basis of differences in their architecture.

\section{Materials and methods}

Filtration experiments were carried out in a $25 \mathrm{~mm}$ diameter Amicon stirred cell from EMD Millipore, USA using $25 \mathrm{~mm}$ diameter membrane discs. Commercial PAA membranes with $20 \mathrm{~nm}$ pore rating (Whatman ${ }^{\circledR}$ Anodisc $^{\text {TM }} 25$, GE Healthcare, UK) and three polyethersulfone (PES) ultrafiltration membranes (Biomax ${ }^{\circledR}$, EMD Millipore, USA) of 100,300 and $500 \mathrm{kDa}$ ratings (as rated by the manufacturer) were used. PAA membranes had a $3 \mathrm{~mm}$ wide polypropylene support ring hence reducing the effective diameter to $19 \mathrm{~mm}$. Bovine serum albumin (BSA) and bovine thyroglobulin (TG) were obtained from Sigma-Aldrich, USA. Protein nanoparticles were synthesised from BSA as mentioned below in section 2.1. BSA, TG and BSA NP were used as model protein solutes. Feed solutions of BSA, TG and BSA NP were prepared in phosphate buffer saline at $\mathrm{pH} 7.4$ with respective concentrations of $1.0,0.2$ and $1.0 \mathrm{mg} / \mathrm{mL}$ as measured using absorbance at $280 \mathrm{~nm}$ wavelength. TG at $0.2 \mathrm{mg} / \mathrm{mL}$ corresponded to approximately $10^{18}$ particles $/ \mathrm{mL}$ as estimated from molecular weight of the TG and Avogadro's number. For BSA NP, $1.0 \mathrm{mg} / \mathrm{mL}$ concentration corresponded to a particle titre of $1-3 \times 10^{11}$ particles $/ \mathrm{mL}$ as measured using nanoparticle tracking analysis (Nanosight LM-10, Malvern Panalytical, UK). Powders of monodisperse GPC-standard dextrans $(5,12,25,50,80,120$, 250,450 and $660 \mathrm{kDa}$ ) and polydisperse dextrans (6, 40, 450 and $2000 \mathrm{kDa}$ ) were obtained from Sigma-Aldrich, USA and Denmark respectively. Size exlusion columns, TSKgel3000SWXL and TSKgel5000PWXL were obtained from Tosho Biosciences GmBH, Germany. Size exclusion column, BioSEC-5 was obtained from Agilent,USA.

\subsection{Preparation of BSA nanoparticles}

A protocol for albumin nanoparticle synthesis was adopted from Storp et al.[25] and modified for use with bovine serum albumin in a shorter preparation time of 4 hours. BSA solution of $100 \mathrm{~g} / \mathrm{L}$ was prepared in $10 \mathrm{mM} \mathrm{NaCl}$ solution and the $\mathrm{pH}$ of the solution was adjusted to 8.0 using $1 \mathrm{M} \mathrm{NaOH}$ and subsequently filtered through a $0.22 \mu \mathrm{m}$ PES syringe filter. BSA solution $(1 \mathrm{~mL})$ was precipitated by addition of a desolvating mixture $(\sim 2-3 \mathrm{~mL})$ of methanol and ethanol in the ratio of 70:30 at a flow rate of $1 \mathrm{~mL} / \mathrm{min}$ while the protein solution was stirred at $550 \mathrm{rpm}$ using a magnetic stirrer and bar. Glass beaker of $25 \mathrm{~mm}$ diameter and $60 \mathrm{~mm}$ height and stirrer bar of $6 \mathrm{~mm}$ diameter and $20 \mathrm{~mm}$ length were used. Addition of the desolvating mixture was stopped as soon as protein solution turned turbid and was then spiked with $60 \mu \mathrm{L}$ of $8 \%(\mathrm{v} / \mathrm{v})$ glutaraldehyde solution to cross-link the nanoparticles. Crosslinking was carried out for 2 hours at room temperature at the same stirring conditions. At the end of crosslinking, the nanoparticle preparation was diluted approximately 50 -fold in the buffer solution and analysed using dynamic light scattering for the particle size distribution. 
112 A mixture of four polydisperse dextrans in $20 \mathrm{mM}$ phosphate buffer,pH 7.0 (with final concentrations

113 of $1,1,1$ and $0.5 \mathrm{mg} / \mathrm{mL}$ of $6,40,450$ and $2000 \mathrm{kDa}$ dextrans respectively) was filtered through

114 membranes in a $25 \mathrm{~mm}$ stirred cell at constant filtrate flux of $\sim 5.5 \mathrm{LMH}(1.5-1.6 \mu \mathrm{m} / \mathrm{s})$ using a 115 peristaltic pump (120U, Watson Marlow) and a stirring rate of $1000 \mathrm{rpm}$. Approximately $20 \mathrm{~L} / \mathrm{m}^{2}$ of the

116 dextran feed was filtered and recirculated back to the stirred cell for two recirculation cycles as

117 described in a similar protocol reported [28]. Final filtrate solution in the tubing and feed solution in the

118 stirred cells were sampled and injected on to a size exclusion column, TSKgel5000PWXL $(7.8 \times 300$

$119 \mathrm{~mm}$ ), pre-equilibrated with $20 \mathrm{mM}$ phosphate buffer at a flow rate of $0.3 \mathrm{~mL} / \mathrm{min}$. Refractive index

120 detector, RID-20A (Shimadzu,UK) was used for detection of the dextran peaks. Calibration plot

121 between peak elution volume and log value of the molecular weight of dextrans was obtained using

122 injections of various monodisperse standard dextrans (5 to $660 \mathrm{kDa}$ ). Size exclusion chromatograms

123 of the feed and filtrate samples were transformed by converting the elution volume into log molecular

124 weight using the calibration equation. A continuous sieving curve was obtained by dividing the signals

125 of filtrate with those of the feed at corresponding molecular weights from the transformed

126 chromatograms.

$127 \quad 2.3$ Protein filtration experiments

128 PAA membranes were rinsed in $20 \%$ ethanol followed by pre-filtered and deionised water. PES

129 membranes were rinsed thrice for 20 minutes using pre-filtered and deionised water as per

130 manufacturer's instructions to remove any preservative. Initial buffer flux ( $\left.\mathrm{J}_{0}\right)$ was measured for clean

131 membranes by filtering $20 \mathrm{~L} / \mathrm{m}^{2}$ of the pre-filtered buffer solution at the transmembrane pressure of

1320.6 bar and a stirring rate of $1500 \mathrm{rpm}$. Equal membrane loadings $\left(26.5 \mathrm{~L} / \mathrm{m}^{2}\right)$ and conversion ratio

$133(75 \%)$ or filtrate outputs $\left(20 \mathrm{~L} / \mathrm{m}^{2}\right)$ were used for both membranes. The transmembrane pressure of

1340.6 bar was used for all protein filtration experiments. After filtration of protein solutions, retentate

135 solution was carefully aspirated out. The membranes surface along with the stirred cell were rinsed

136 three times with the buffer solution, and buffer flux was measured again in the same manner as for

137 the initial buffer flux. Flux recovery ratio (FRR, \%) was measured as a percentage of the initial buffer

138 flux measured post filtration and rinsing. Filtrate, feed and retentate samples were collected and

139 analysed for protein quantification using size exclusion chromatography as described in section 2.5.

140 Recovery of the protein was calculated using the peak areas of the proteins in samples and feed

141 solution and considering total volumes of the samples.

$142 \quad 2.4$ Fractionation experiment

143 A mixture of 80nm BSA nanoparticles and BSA was prepared in PBS with a final concentration of 1

$144 \mathrm{mg} / \mathrm{mL}$ for both solutes. Fractionation was carried out in a sequential or discontinuous diafiltration

145 mode after an initial concentration step. Equal membrane loadings of $\sim 26 \mathrm{~L} / \mathrm{m}^{2}$ were applied on all the

146 membranes and feed was initially concentrated 4-fold volumetrically. The retentate was then

147 subjected to 12 diafiltration steps in sequence. Each diafiltration step involved a manual 2 -fold dilution 
of the retentate with PBS followed 2-fold concentration thus each diafiltration step corresponding to one diavolume of the buffer exchanged. A transmembrane pressure of 0.6 bars and the maximum stirring speed of $1500 \mathrm{rpm}$ was used for the initial concentration step and subsequent diafiltration steps. Filtrate collected for all steps of the UF/DF process and final retentate samples were analysed for the model solutes using size exclusion chromatography as described in section 2.5. Purification factor for the protein nanoparticles was calculated in the retentate as explained in [29].

\subsection{Protein quantification using size exclusion chromatography}

Feed, filtrate and retenate samples from filtration experiments were analysed with size exclusion chromatography using Agilent 1260 HPLC system with a diode array detector. For TG and BSA, 50 $\mu \mathrm{L}$ of sample was injected onto a TSKgel3000SWXL $(7.8 \times 300 \mathrm{~mm})$ with $30 \mathrm{~nm}$ pores at a flow rate of $0.6 \mathrm{~mL} / \mathrm{min}$. For BSA NP, $20 \mu \mathrm{L}$ of sample was injected onto a BioSEC5 $(7.8 \times 300 \mathrm{~mm})$ with $100 \mathrm{~nm}$ pores at a flow rate of $0.8 \mathrm{~mL} / \mathrm{min}$. PBS was used as the equilibration and elution buffer for both columns. Proteins were detected by measuring absorbance at a wavelength of $280 \mathrm{~nm}$. Calibration of the columns was tested using gel filtration standard from Biorad, UK.

\section{Results and discussion}

\subsection{Selection of the model protein solutes}

Bovine serum albumin (BSA) of $67 \mathrm{kDa}$, thyroglobulin (TG) of $670 \mathrm{kDa}$ and albumin nanoparticles (BSA NP) were chosen as model solutes for host cell proteins, small viral vectors such as adeno-associated viruses and larger viral vectors such as adenoviruses respectively. The mean hydrodynamic diameter of these solutes was measured to be $\sim 8.7 \mathrm{~nm}$ for BSA, $\sim 21 \mathrm{~nm}$ for TG and 80-90 nm for NPs as shown in Fig. 1 corresponding to the reported sizes of the abovementioned viral vectors [30].

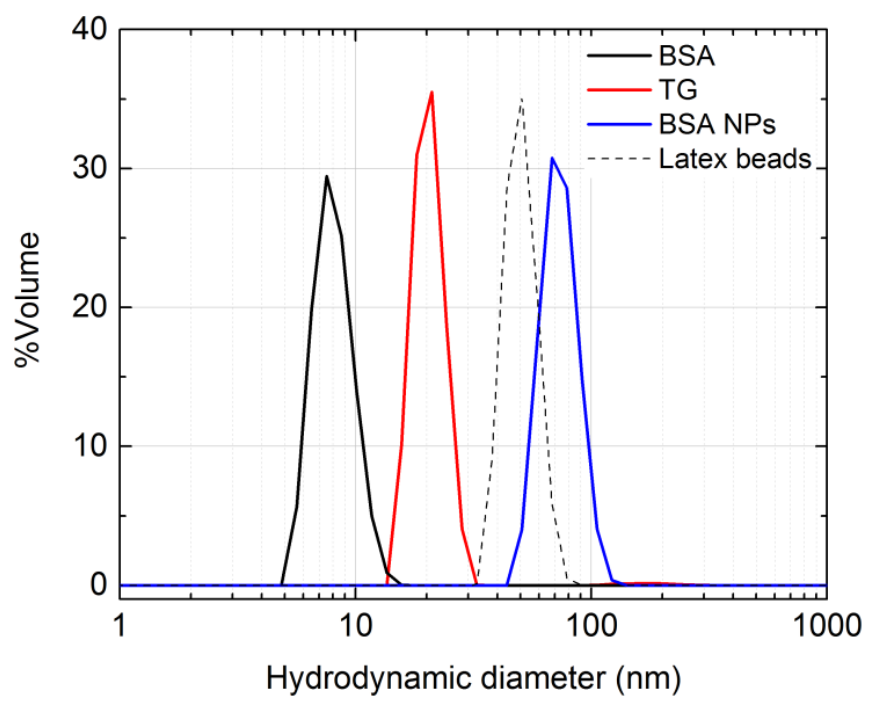

Fig. 1 Particle size distribution of the three model solutes used in the present study obtained from dynamic light scattering measured and analysed using Zetasizer NS (Malvern Panalytical, UK) Monodisperse latex beads of $47 \mathrm{~nm}$ were used to check the calibration of the instrument. 
173 For nanoparticle preparation, more than $98 \%$ of the BSA was found to be converted into the

174 nanoparticles as observed using size exclusion chromatography. Both BSA and TG preparations also

175 had higher molecular weight components as shown by the size exclusion chromatography (see Fig.

176 A.1 for size exclusion chromatogram of BSA solution). The presence of these high molecular weight

177 components in BSA ranging from $66 \mathrm{kDa}$ of the monomer and $300 \mathrm{kDa}$ multimers is useful to

178 characterise the fractionation performance of the membranes if they are to be used to separate viral

179 particles from the smaller proteins impurities such as host cell proteins which have been reported to

180 be in range of 25 to $300 \mathrm{kDa}$ with majority in range of $50-100 \mathrm{kDa}$ [26].

$181 \quad 3.2$ Selection of an appropriate polymeric ultrafiltration membrane for comparability studies

182 Since polymeric ultrafiltration membranes are available in various ranges of materials and ratings,

183 selection of the appropriate membrane rating is crucial for proper comparison with the selected PAA

184 membranes. Commercial polyethersulfone (PES) membranes were selected over cellulose-based

185 membranes due to high permeability of the former as indicated by the manufacturer. Further,

186 polymeric membranes and porous anodic alumina membranes are rating differently. Membrane

187 ratings for polymeric membranes are usually expressed as their molecular weight cut off (MWCO)

188 limits in kiloDaltons using dextran sieving. PAA membranes on the other hands are rated by the mean

189 value of the pore size distribution of the active layer pores usually using electron microscopy.

190 Polymeric ultrafiltration membranes rated 100, 300 and $500 \mathrm{kDa}$ were compared against the $20 \mathrm{~nm}$

191 rated PAA membrane for similar hydraulic permeability and dextran sieving characteristics.

192 Out of three rating for the PES membrane, $300 \mathrm{kDa}$ PES was found to have the most similar hydraulic

193 permeability compared to the PAA membranes as shown in Fig. 2 and Table 1. Similar hydraulic

194 permeability would indicate similar convective mass transfer for solvent, and similar dextran sieving

195 characteristics would indicate similar intrinsic solute transport characteristics between the two

196 membranes. It should be noted that the coefficient of variation (CoV) of hydraulic permeability of the

197 membrane is higher for large MWCO polymeric membranes (10 and $37 \%$ for 500 and $300 \mathrm{kDa}$ PES

198 membranes respectively) compared to the $20 \mathrm{~nm}$ PAA (5\% CoV) and 100kDa PES membrane (3\%

199 CoV). Large coefficient of variation for the $300 \mathrm{kDa}$ PES membrane was attributed to filter to filter

200 variability as no outlier was detected in a dataset of 9 membrane discs from the same membrane lot. 


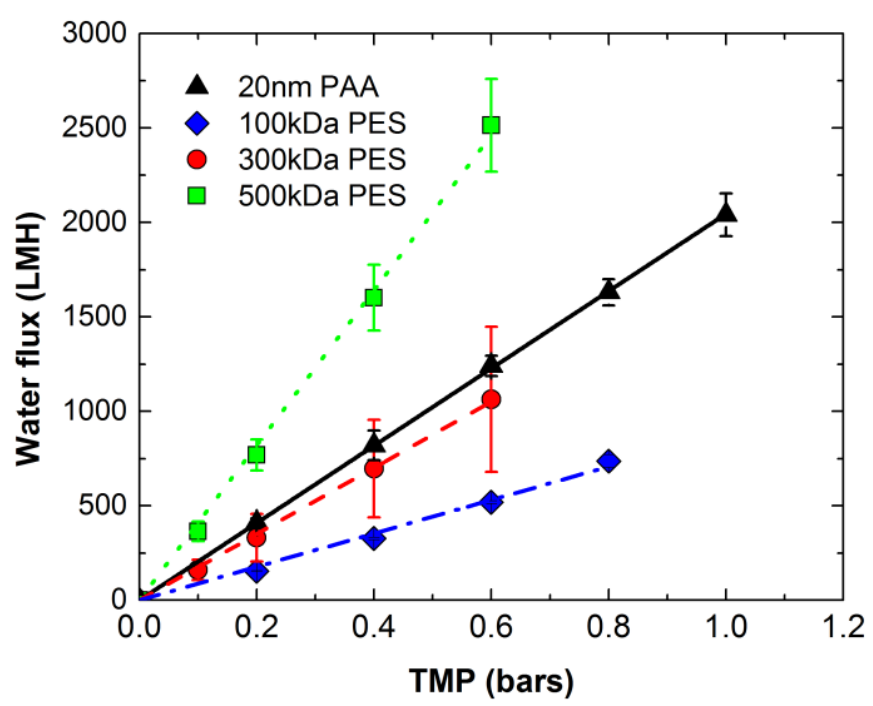

201

Fig. 2 Water fluxes at different transmembrane pressure for calculation of hydraulic permeability of 20nm rated PAA and PES membranes of different ratings. Fluxes were measured at room temperature $\left(22-23^{\circ} \mathrm{C}\right)$ and using pre-filtered deionised water. The lines represent linear fit of the data points. The slope of the graph represents the hydraulic permeability value of the membranes and error bars represent one standard deviation across the mean values of flux for multiple membranes ( $n=9$ for $300 \mathrm{kDa}$ PES and $20 \mathrm{~nm}$ PAA; $n=3$ for 100 and $500 \mathrm{kDa}$ PES). LMH represents the unit of flux in $\mathrm{L} \mathrm{m}^{-2} \mathrm{hr}^{-1}$.

Dextran sieving curves, as shown in Fig.3, for both membranes were obtained using the same protocol. Though none of the polymeric membranes perfectly resembles the dextran sieving characteristics of the PAA membranes, sieving curve for the $300 \mathrm{kDa}$ polymeric membrane appears to be closer to that of the 20nm PAA membrane. Dextran ratings (for $90 \%$ rejection) obtained for both 300 and $500 \mathrm{kDa}$ rated polymer membranes were larger compared to the ratings provided by the membrane manufacturer as shown in Table 1. Dextran rejection rating for $500 \mathrm{kDa}$ could not be measured as the value was beyond the exclusion limit $(1000 \mathrm{kDa})$ for the size exclusion column used in the experiment. For the membrane rated $300 \mathrm{kDa}$ by the manufacturer, estimated dextran rating for $90 \%$ rejection was found to be 6 times larger than the specified rating. Such variations have been previously reported due to lack of a standardised dextran sieving tests resulting in variation of the methodology used including feed composition [31] and filtration modules [32] employed for dextran sieving tests. The stirred cell used in the current study was $25 \mathrm{~mm}$ in diameter which has been reported to have increased sieving compared to cells with larger diameters [32]. While larger stirred cells of 45 and $63 \mathrm{~mm}$ diameters were available, the largest available PAA membrane discs were 47 $\mathrm{mm}$ which were not compatible with either of the stirred cells. It was crucial to use the same stirred cell for both membranes to avoid different polarisation conditions due to the different size of modules. 


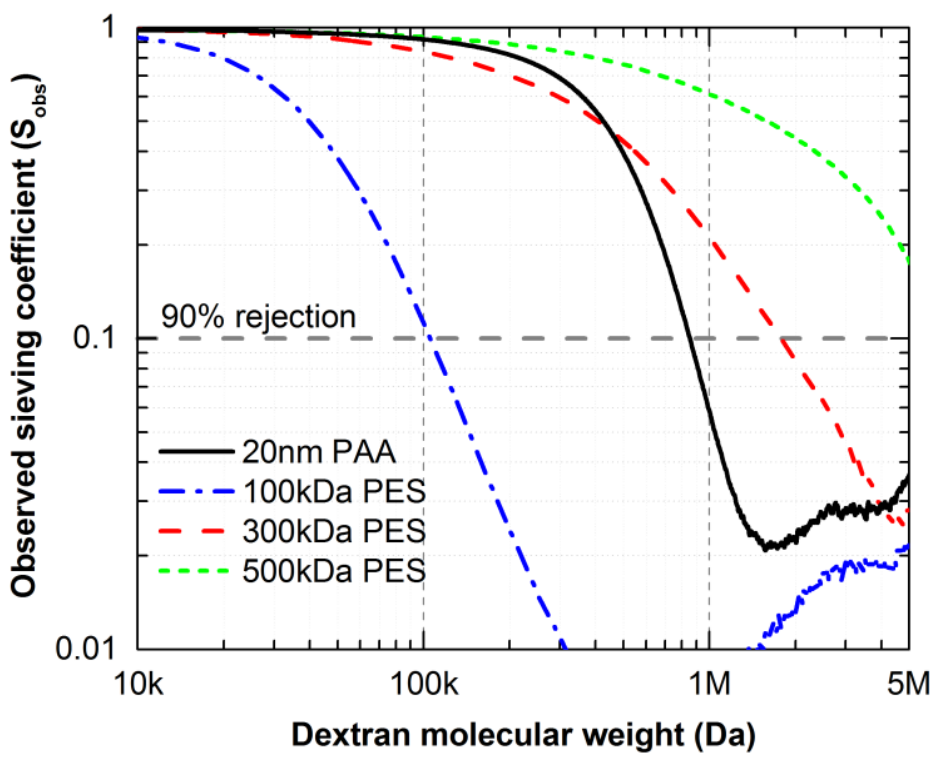

Fig. 3 Dextran sieving curves for porous anodic alumina (PAA) membrane rated 20nm and polyethersulfone (PES) membranes rated 100, 300 and $500 \mathrm{kDa}$. The horizontal grey line represents $90 \%$ rejection (observed sieving coefficient of 0.1 ) and is used to compare the dextran rating of the membranes by measuring corresponding values of $\mathrm{X}$-axis at the point of intersection of the grey line and dextran sieving curve for each of the membranes.

A common dextran sieving test for PAA and PES membranes was useful to compare the effect of pore size distributions despite difficulty in the comparability of absolute ratings for the membranes. This is evident from the sharper curve obtained for the PAA membrane. Dextran being neutral solute does not have any electrostatic interactions with membrane material, and transport of dextrans is purely steric. Thus any variation in the solute transport should be purely due to membrane architecture and not affected by the surface chemistry of the membrane material. Hence for membranes with similar convection and dextran transport properties, any differences observed during protein filtration could be attributed to the mechanisms of retention and fouling. Differences in the membrane architecture were confirmed by imaging the active layer surface and cross-section of the PAA and $300 \mathrm{kDa}$ PES membranes. PAA membranes show straight pore channels and narrow pore size distribution of the active layer surface as shown in Fig. 4. Larger pores can be observed in the active layer surface of the $300 \mathrm{kDa}$ PES membrane. 
A

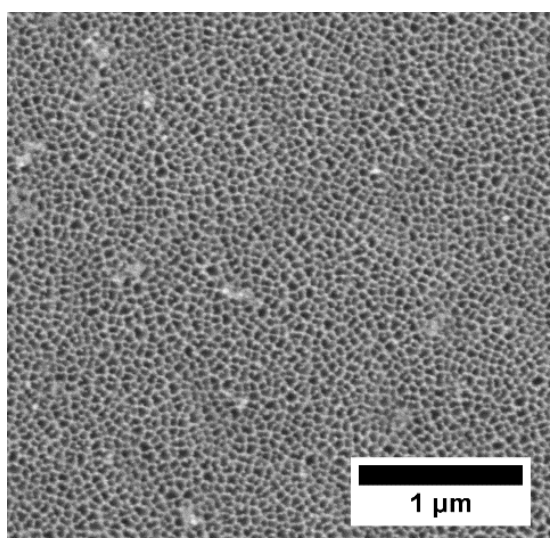

C

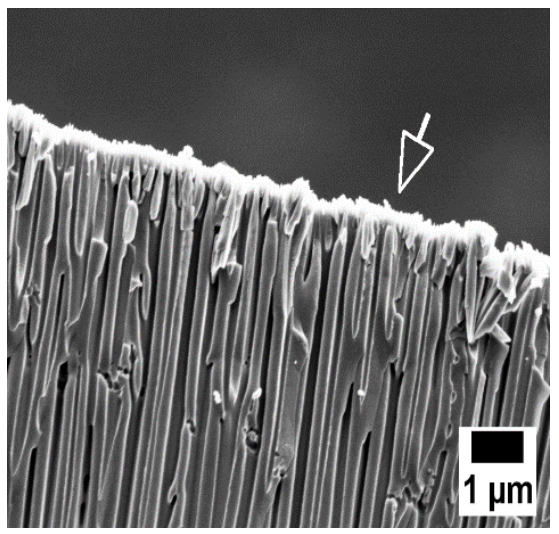

B

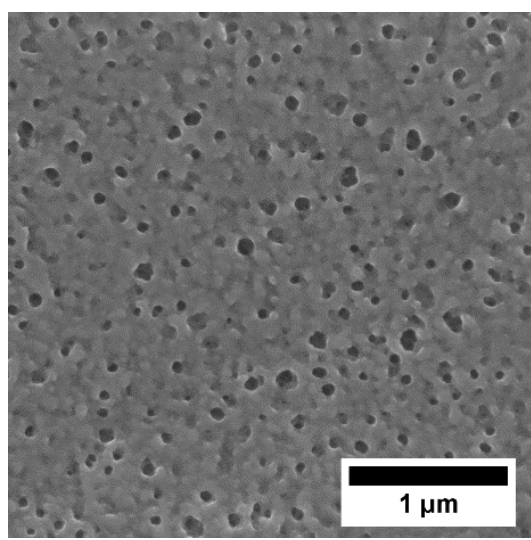

D

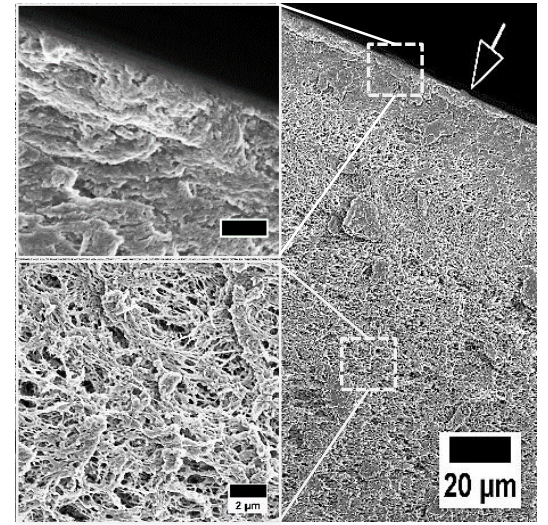

244 Fig. 4 Scanning electron microscopy images of the active layer surface (top) and cross section
245 (bottom) of 20nm rated PAA ( $A$ and C) and $300 \mathrm{kDa}$ PES membranes (B and D). Images of active layer surface $(A$ and $B)$ were obtained at the same magnification factor $(50,000 \mathrm{X})$ for the membranes. Active and intermediate layers of the PES membranes are shown in the inset (scale bars $=\mathbf{2} \boldsymbol{\mu m}$ ) of $\mathrm{D}$ as $\mathbf{1 0}$-fold magnified images of respective areas. Arrows indicate the active layer side of the membranes. Images were obtained using InLens detector of Zeiss Gemini Sigma electron microscope (Carl Zeiss AG, Germany) at a gun voltage of $5 \mathrm{kV}$ after

251 platinum coating of the samples.

\begin{tabular}{lll}
\hline $\begin{array}{l}\text { Membrane } \\
\text { (With }\end{array}$ & $\begin{array}{l}\text { Hydraulic permeability } \\
\text { (LMH/bar) }\end{array}$ & $\begin{array}{l}\text { Dextran rejection (90\%) rating } \\
(\mathbf{k D a})\end{array}$ \\
$\begin{array}{l}\text { specified ratings) } \\
\mathbf{1 0 0} \text { kDa PES }\end{array}$ & $890 \pm 30$ & \\
\hline $\mathbf{3 0 0}$ kDa PES & $1750 \pm 640$ & 105 \\
\hline $\mathbf{5 0 0}$ kDa PES & $4100 \pm 420$ & 2000 \\
\hline $\mathbf{2 0} \mathbf{~ n m ~ P A A ~}$ & $2050 \pm 100$ & $\mathrm{NM}$ \\
\hline
\end{tabular}


255 Based on hydraulic permeability and dextran sieving characteristics, we selected $300 \mathrm{kDa}$ rated PES membranes for comparison with 20nm PAA membranes for further filtration experiments using the model protein solutes.

\subsection{Filterability of solutions of the model protein solutes}

PAA membranes showed better filterability for all protein solutions compared to the PES membranes as shown by higher cumulative filtrate fluxes in Fig. 5. As both membranes had different permeability the process flux values were normalised to the initial buffer fluxes measured at the same transmembrane pressure. PAA membranes operated at higher normalised flux values compared to the PES membranes even for BSA nanoparticles where the difference was smaller but still significant. Interestingly, the PES membranes operated at a value of $50 \%$ of the initial buffer flux for BSA filtration, but no flux decline was captured in the experimental data. This was likely due to the presence of the high molecular weight species (150-300 kDa) in the BSA preparations resulting in immediate clogging of some of the pores. It was found that the filter discs used for BSA filtration had very low permeability values ( 900 LMH/bar) compared to the mean value for the entire lot (1750 $\mathrm{LMH} / \mathrm{bar}$ ). This was a result of random selection of the filter disc from same lot and high filter to filter variability with $300 \mathrm{kDa}$ PES membrane. Such low permeability value indicate a smaller mean pore size of the membrane which can make it susceptible to fouling by larger species in BSA feed. BSA did not result in any significant flux decline for PAA membranes as the membranes operated at $\sim 90 \%$ value for the normalised flux throughout the filtration run which is discussed in next section when transmission of the solutes is compared. 

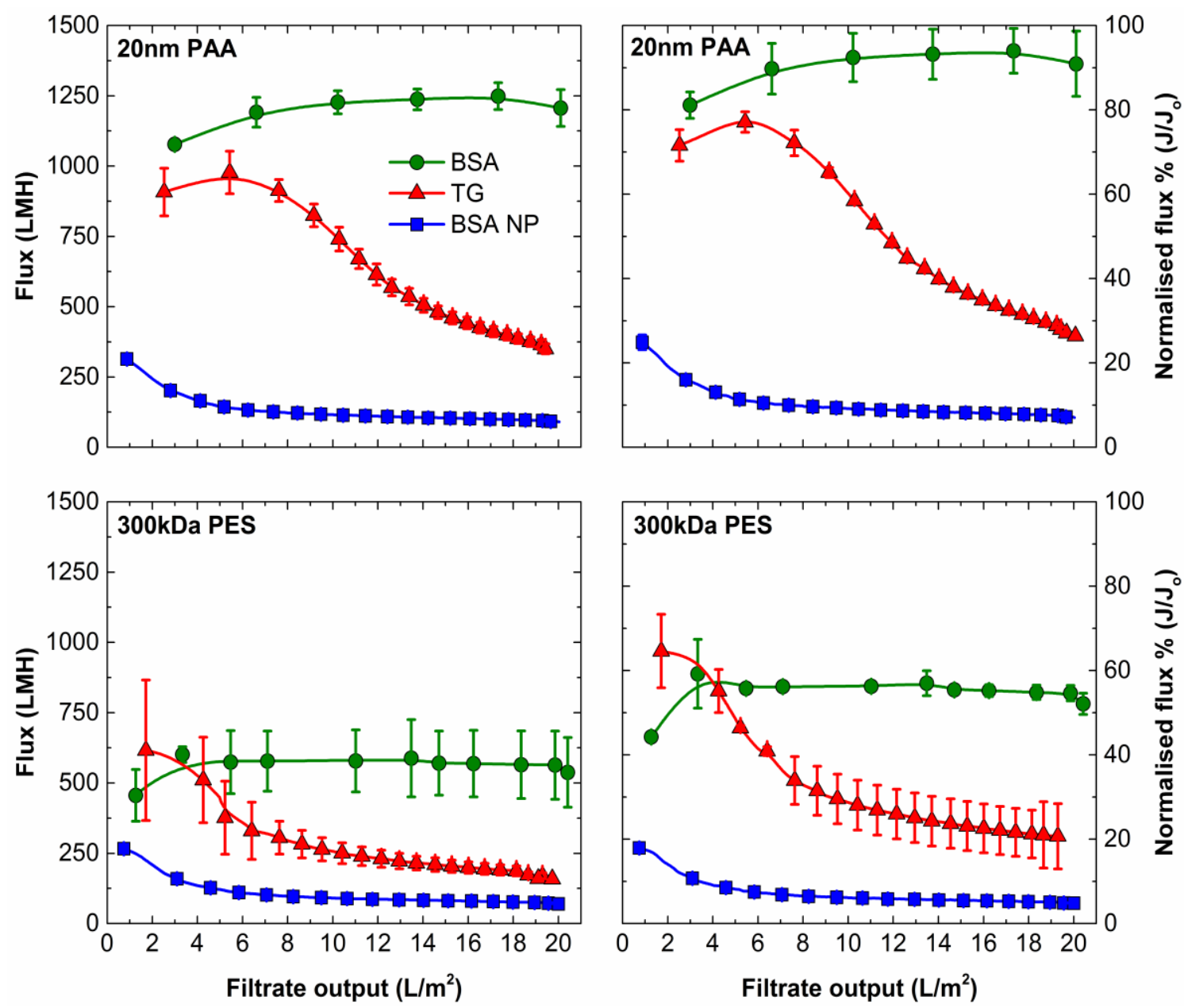

276 Fig. 5 Flux decline (absolute flux values on the left side plots and flux normalised to the initial 277 buffer flux on the right side plots) observed for filtration of solutions of model protein solutes through $\mathbf{3 0 0} \mathrm{kDa}$ rated PES and $20 \mathrm{~nm}$ rated PAA membranes. Symbols and error bars represent the average values and one standard deviation respectively for triplicate filtration runs. The transmembrane pressure of 0.6 bar and a stirring rate of $1500 \mathrm{rpm}$ was used.

TG and BSA nanoparticles resulted in significant flux decline for both membranes as filtration progressed. However, the shape of the flux decline curves for TG was different for both membranes suggesting different mechanisms of the flux decline. Analysis of the raw filtration data (volume and time) for identification of the dominant fouling mechanism was carried out as described by Bolton et al., [27]. Models were constrained to a single output parameter by using the experimental values of initial buffer flux through the membrane. Mathematical expressions and the results of curve fitting are provided in table B.1 and B.2 respectively in appendix B.

Fig. 6 shows curve fits for the TG and BSA nanoparticle filtration with four fundamental mechanisms of the fouling. The best curve fit with the highest regression coefficient and lowest sum of the square of residuals (SSR) was interpreted as the dominant fouling mechanism responsible for the flux decline. As speculated from the flux decline curves, mechanisms of fouling by TG were different for the two membranes. Intermediate blocking was identified as the dominant mechanism of flux decline 
in the PAA membrane, and cake filtration was dominant for the PES membrane. For BSA nanoparticles, the quality of the curve fitting was not as good as obtained for TG. Both membranes showed cake filtration as the closest best fit with the experimental filtration data. Interestingly, both membranes showed high flux decline in the initial filtration period where experimental data is well below the best-fit curve for cake filtration. It suggests that the mechanism of flux decline for BSA nanoparticles has 'cake-like' resistance for convection across the membranes. It should be noted that the confidence on the validity of these model fits for BSA nanoparticles is low as the value of sum of the squares of residuals (SSR) was about a magnitude higher compared to those observed for TG filtrations. SEM images of the BSA NP fouled surfaces of the membranes (Fig. C.1 and Fig D.1 in Appendices) also do not show a thick and uniform layer. It is more likely that flux decline is through a different mechanism such as osmotic pressure or concentration polarisation. It is also possible that multiple fouling mechanisms are responsible for such behaviour. Combined models of fouling were attempted but the fits were over-parameterised, thus not considered valid. It should be noted that models of the fouling mechanisms are often developed and validated for microfiltration or depth filtration membranes and for purely dead-end filtration without any stirring on the membrane surface. Our experiments were performed using the dead-end mode with high stirring speed above the membrane surface which will impact cake as well as concentration polarisation above the membrane surface. 

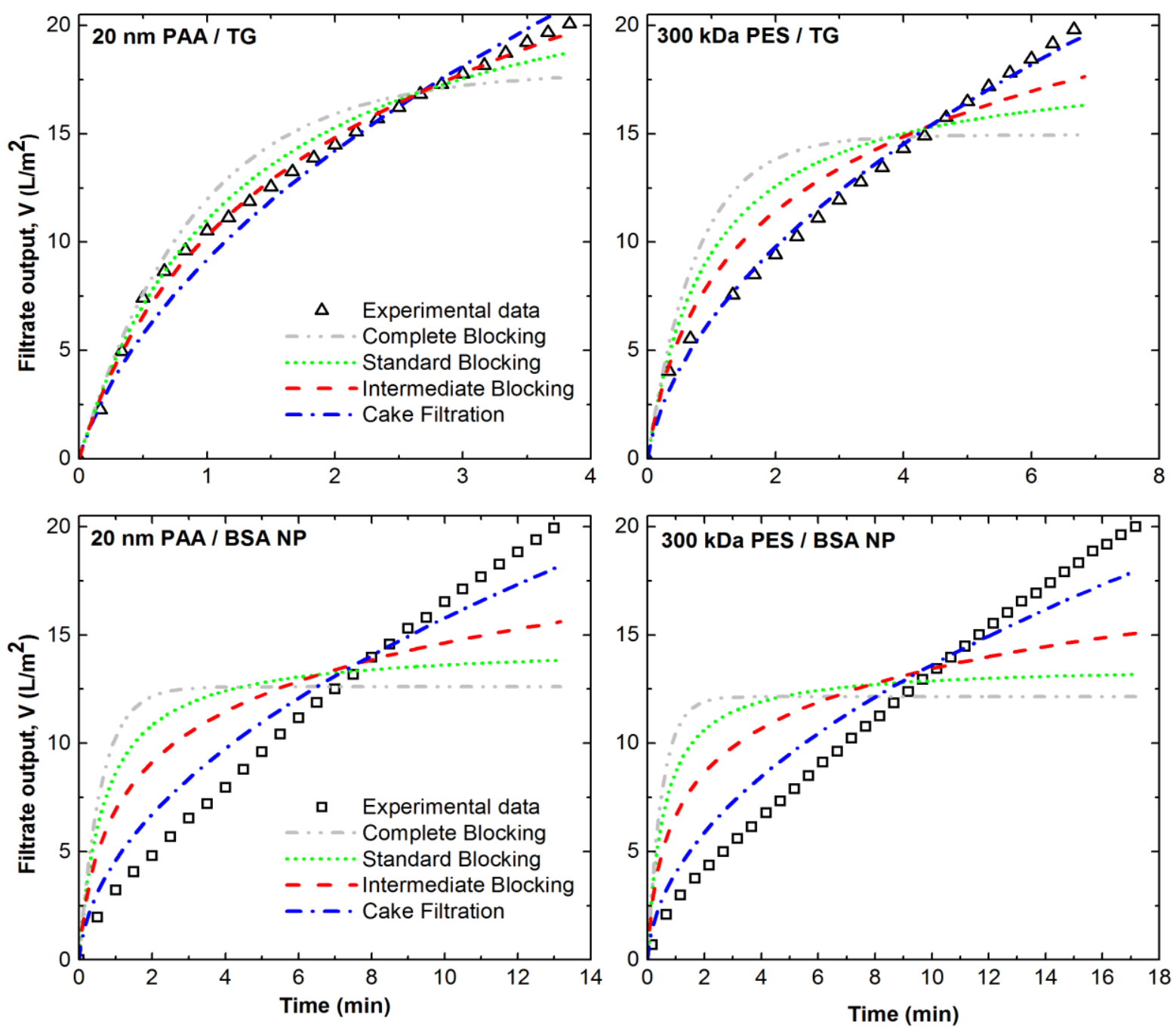

Fig. 6 Experimental data (open symbols) for TG and BSA nanoparticle filtration through PAA and PES membranes along with best-fitted curves (lines) for four fundamental mechanisms of fouling. Filtrate output is normalised with the membrane area. Mathematical expressions of the fouling models used and output data for curve fitting including goodness-of the fit data is given in table B.1 and B.2 respectively in appendix B.

\subsection{Transmission of the model protein solutes}

Both membranes show high transmission of BSA ( $>95 \%)$ and transmission of the solutes reduced with an increase in the solute size as expected. PAA membranes, however, showed a higher transmission of the larger model solutes (TG and BSA NP) compared to the PES membrane as shown in Fig. 7. Higher transmission of BSA nanoparticles through 20nm PAA membranes was unexpected as nanoparticles are more than 2-3 folds larger than the pore rating of the PAA membranes. SEM analysis of the active layer surface of the PAA membranes revealed that the mean pore size of the active layer surface was larger than $20 \mathrm{~nm}$ pore rating. A mean pore size of $55 \pm 7 \mathrm{~nm}$ was estimated from image analysis of the SEM images of active layer of the membranes using Image $\mathrm{J}$, but the distribution was narrow and maximum pore diameter was not larger than the mean size of nanoparticles. Pore size distribution of the $300 \mathrm{kDa}$ PES membrane showed the presence of large 
pores and despite this lower transmission of BSA NP was observed. Pore size distributions of membranes are provided in Appendix F. Particle size distribution of the retentate obtained using PAA membrane did not show any significant difference from that of the initial feed solution which ruled out a favourable transmission of a sub-population of BSA NP (with size smaller than $55 \mathrm{~nm}$ ) through larger pores in the pore size distribution of the PAA membrane. SEM imaging over a broad surface area of the PAA membranes revealed patches of the surface where the active layer was missing as shown in Fig. 8, exposing the support layer underneath which has a larger mean pore diameter of 200 nm. Such large defects have been reported in commercial PAA membranes [18] and are attributed to the fabrication conditions.

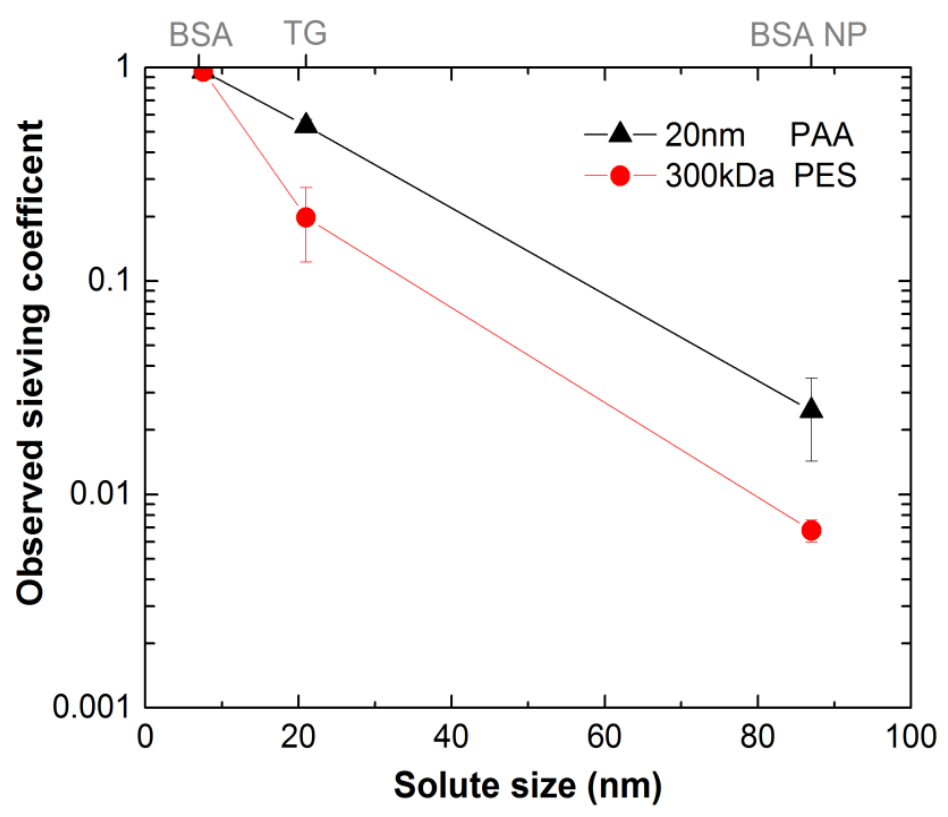

Fig. 7 Transmission of different model solutes through $20 \mathrm{~nm}$ rated PAA, and $300 \mathrm{kDa}$ rated PES membranes. Observed sieving coefficient represents the ratio of the solute concentration in the collected filtrate and initial feed solution. Data points and error bars represent average values for triplicate runs and one standard deviation across the average respectively.

The presence of these large surface defects could explain almost four-fold higher transmission of the BSA nanoparticles through the PAA membrane. Random distribution of these large defects and limited scanning area capability of SEM makes it difficult to obtain an accurate count of such defects and their contributions to the buffer flow rate and solute transmission across the membrane. Since defect free membrane discs were not available, the impact of these surface defects on the hydraulic permeability of the membrane could not be experimentally measured. Even higher hydraulic permeability of $1.2047 \times 10^{-8} \mathrm{~m} / \mathrm{Pa}$.s ( 2 times than $5.7 \times 10^{-9}$ measured in this study) has been previously reported [19] for 20nm PAA membrane indicating that such density of such large surface defects may even vary among different membrane lots. Compromised sealing of the PAA membrane discs due to the support ring on the membrane disc was ruled out since reasonable water flow rates were observed through the membranes even at high pressure (1 bar). Also a compromised sealing would likely result almost complete solute transmission even for large solutes which was not 
observed. Higher transmission of protein solutes through the PAA membrane was also the opposite of the trend observed for sieving of the large dextrans as shown in Fig. 3. Especially for a molecular weight of $670 \mathrm{kDa}$, which is the molecular weight of thyroglobulin, sieving coefficients for thyroglobulin and dextran molecule of same molecular weight were found to be $0.60 \pm 0.04$ and $0.21 \pm 0.01$ respectively. Likely reason for lower sieving coefficient for dextran molecules could be due to larger hydrodynamic size of the dextran. Stokes diameter for $670 \mathrm{kDa}$ dextran molecule was calculated to $\sim 36 \mathrm{~nm}$, larger than $\sim 16 \mathrm{~nm}$ calculated for $670 \mathrm{kDa}$ thyroglobulin molecule using M.W. and Stokes radius correlation described elsewhere [33]. For 300kDa PES, observed sieving coefficients were higher for thyroglobulin $(0.21 \pm 0.08)$ compared to dextran of equal molecular weight $(0.39 \pm 0.08)$. Lutz [33] have pointed out that due to linear shape of the dextrans, the molecules will tend to align with their larger diameter perpendicular to the pore entrance thus resulting in larger transmission compared to the globular molecules like proteins. This hypothesis appears to be true for PES membranes. Besides size differences other possible explanations for this could be the very low polarising operating conditions of the dextran sieving experiments (constant flux of $5 \mathrm{LMH}$ and stirring speed of $1000 \mathrm{rpm}$ compared to variable flux of 2400 to $70 \mathrm{LMH}$ for protein filtration experiments under constant positive pressure of 0.6 bar), the neutral charge of the dextrans and linear shape of the dextran molecules in contrast to the charged and globular protein solutes. It is unclear if the membrane architecture and surface defect of PAA membranes played a role in differences in the sieving of dextran and protein molecules.

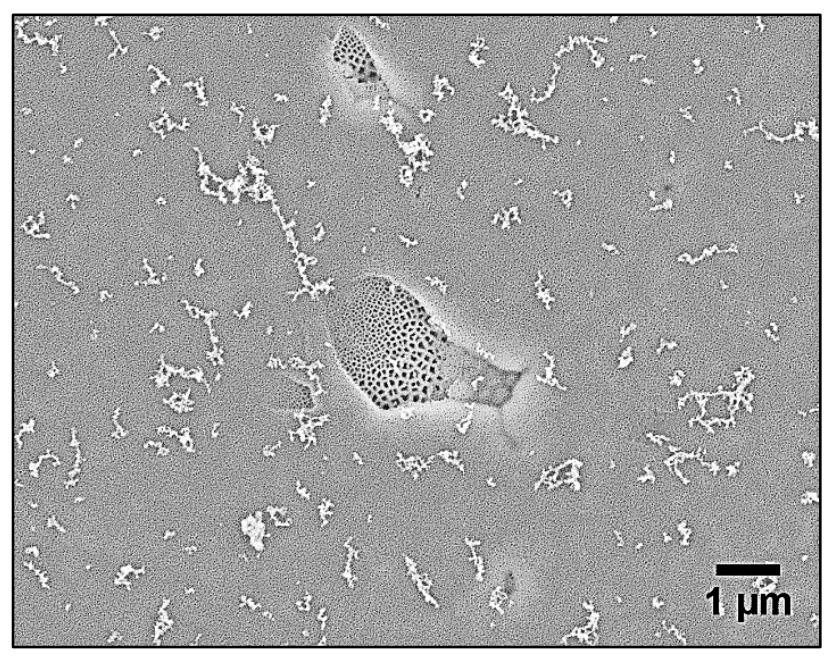

Fig. 8 A low-resolution image of the active layer surface of the $20 \mathrm{~nm}$ rated PAA membranes obtained using a scanning electron microscope (Gemini sigma, Carl Zeiss AG, Germany) showing the large surface defects exposing the underlying support layer with pores of $\sim 200 \mathrm{~nm}$ diameter.

\subsection{Restoration of membrane permeability post filtration}

Fig. 9 shows the distinct performance of the two membranes when compared by membrane permeability post-filtration of different solutes. Restoration of the membrane permeability is indicated by a high value of the flux recovery ratio (FRR). Loosely deposited protein on the membrane surface 
was removed by thoroughly rinsing the membrane surface using buffer solution before measurement of the post-filtration buffer flux. Rinsing the stirred cell also ensured that post filtration buffer flux would not be affected by the residual solute bound on the stirred cell surface. Thus, low FRR values indicate tightly bound proteins on either membrane surface or inside membrane bed which would require physical or chemical treatment for removal. The membrane surface when examined using electron microscopy showed patches of the fouling (see Fig. C.1 and D.1) though the coverage of the membrane surface cannot be correlated with the value of FRR thus suggesting a role of the internal fouling. For both membranes, FRR values were found to be minimum for the filtration of TG. SEM images of the active layer surface of the membranes also showed similar trend with maximum fouling observed for TG fouled membranes (see fig. C.1 and D.1).

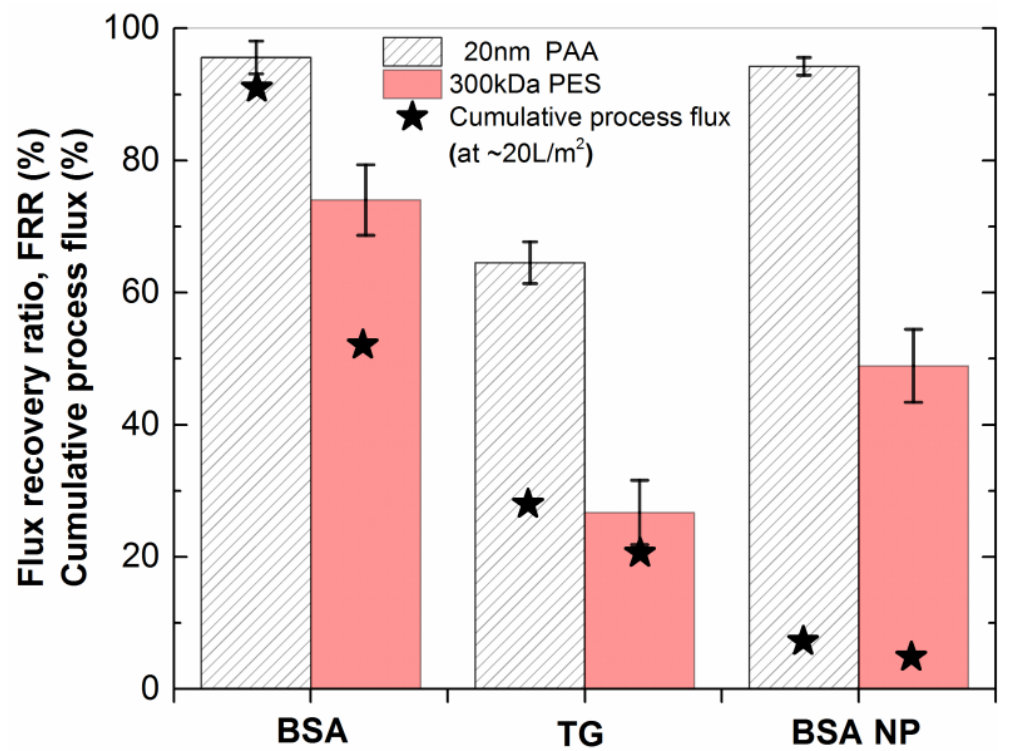

Fig. 9 Recovery of membrane permeability after filtration of different model solutes (BSA, TG and BSA NP) measured as flux recovery ratio (post-filtration buffer flux as $\%$ of the initial buffer flux). Columns represent average value of FRR for triplicate filtration runs and error bars represent one standard deviation across the average value. Star symbols on columns represent the values of the cumulative process flux observed at the end of the filtration (as $\%$ of the initial buffer flux) for corresponding membranes and solutes.

The PAA membrane showed highest internal fouling by TG as indicated by lowest FRR value of $60 \%$ among all three solutes. Hydrodynamic diameter of TG is measured to be $\sim 22 \mathrm{~nm}$ which is approximately half of the measured mean pore size of $55 \mathrm{~nm}$ for the PAA membranes used. Though high transmission of TG could be explained due to the presence of surface defects, it appears that pores in the distribution may also have been accessed by the TG particles eventually blocking them. This is also apparent from the intermediate blocking fouling model predicted for TG filtration where a few particles initially plug some pores and rest of the particles deposit on the plugged pores. SEM images of the TG fouled membrane also show fouling embedded on smaller pores of the membranes (Fig. C.1). Interestingly, both BSA and BSA NP, showed very high FRR values above $90 \%$. For BSA, which has an average hydrodynamic diameter of $8.7 \mathrm{~nm}$, approximately 6 fold lower than the pore 
size, pore plugging would only be for the pores at the lower end of the pore size distribution. It should also be noted that average hydrodynamic diameter of BSA also has contribution from the minor HMW component of the BSA solution and actual hydrodynamic diameter of smaller BSA monomers may be smaller than $8.7 \mathrm{~nm}$, thus having high sieving of the BSA from the pores. With a mean diameter of 80 $\mathrm{nm}$ the BSA NPs are unlikely to enter the smaller pores in the intact active layer of the PAA membrane. FRR value of more than $90 \%$ was observed for $80 \mathrm{~nm}$ BSA NP indicating very little pore plugging by FRR. Restoration of membrane permeability with a simple wash of the membrane surface after protein filtration suggests that the flux decline for BSA nanoparticle filtration is through a pressure dependent and reversible mechanism which manifests immediately as pressure is applied. Concentration polarisation is a pressure dependent and reversible phenomenon which manifests due to an imbalance in solute mass-transfer from bulk solution towards the membrane surface and away from it. Reversibility of the membrane permeability has been previously associated with concentration polarisation based flux decline [34]. SEM image of the active layer surface also shows only a few pores blocked by BSA NP (Fig. C.1).

For the PES membrane, FRR values were significantly lower than those of PAA membranes for all solutes. Notably, only $70 \%$ of the initial membrane permeability is restored after filtration of BSA where membranes operated at $50 \%$ of the initial buffer flux during the filtration as shown in fig 5 . This was likely due to internal fouling caused by high molecular weight components (>150 kDa) observed in the BSA solution. Among all the solutes, the lowest FRR value ( 20\%) was obtained for TG, indicating higher internal fouling. The likely reason is that the molecular weight of TG (660 kDa) is close to the molecular weight cut off of $300 \mathrm{kDa}$ for the membrane, thus making the larger pores of the membrane accessible to the solute. Cake like protein depositions were also observed on the membrane surface fouled by TG when observed using electron microscopy (Fig. D.1). Curve fitting with fouling models also identified cake filtration as the dominant mechanism of fouling for TG filtration through PES membranes. Filtration of BSA nanoparticles showed an FRR value of $50 \%$ significantly lower than 95\% observed for PAA membranes and significantly higher level of fouling observed on active layer surface of the PES membrane as observed using SEM. Higher fouling of the PES membrane by BSA NP could not be explained with the cake filtration model only. Further, coverage of the membrane surface area by BSA NP fouling was not very high indicating presence of internal fouling. Membrane compressibility is unlikely as the polymeric membranes were operated at a transmembrane pressure lower than the maximum operating pressure specified.

The role of solute-membrane interactions to fouling such as electrostatic binding can be ruled out as both membranes have been marketed as low protein binding materials and experiments were carried out at a moderate salt concentration to minimise such non-specific binding. We suggest that the concentration polarisation is the dominant flux decline mechanism for both membranes in the initial filtration window especially for BSA NP. Since the concentration polarisation has been known to increase the leaky transmission of the polarising solute through the membranes [35, 36], model solutes will likely diffuse into the larger pores in the pore size distribution of the membranes. Pores larger than the nanoparticles were observed on the active layer of the PES membranes and in the 
surface defects on the active layer of PAA membranes exposing the large pores of the support layer of the membrane underneath. We hypothesise that the differences in the membrane architecture of the two membranes result in different particle retention mechanisms. PAA membranes are thinner $(\sim 60 \mu \mathrm{m})$ and have near straight channels (low tortuosity). In contrast, the polymeric membrane has thicker active and intermediate layer $(\sim 120 \mu \mathrm{m})$ with highly tortuous channels. Effective diffusional paths for solute particles would be higher for the polymeric membranes compared to the thinner and straight channels of the PAA membranes. Thus, protein nanoparticle diffusing through the smaller and straight channels of the support layers exposed by defects in the PAA membrane will face less resistance compared to diffusion through large surface pores into the tortuous channels across a thicker membrane bed of the PES membrane. This would result in higher transmission of particles through surface defects of PAA membranes without clogging of the smaller pore on the intact active layer of the membrane. Nanoparticles would gradually deposit inside the PES membrane channels due to the highly tortuous path and collision to the channel walls resulting in internal fouling and low

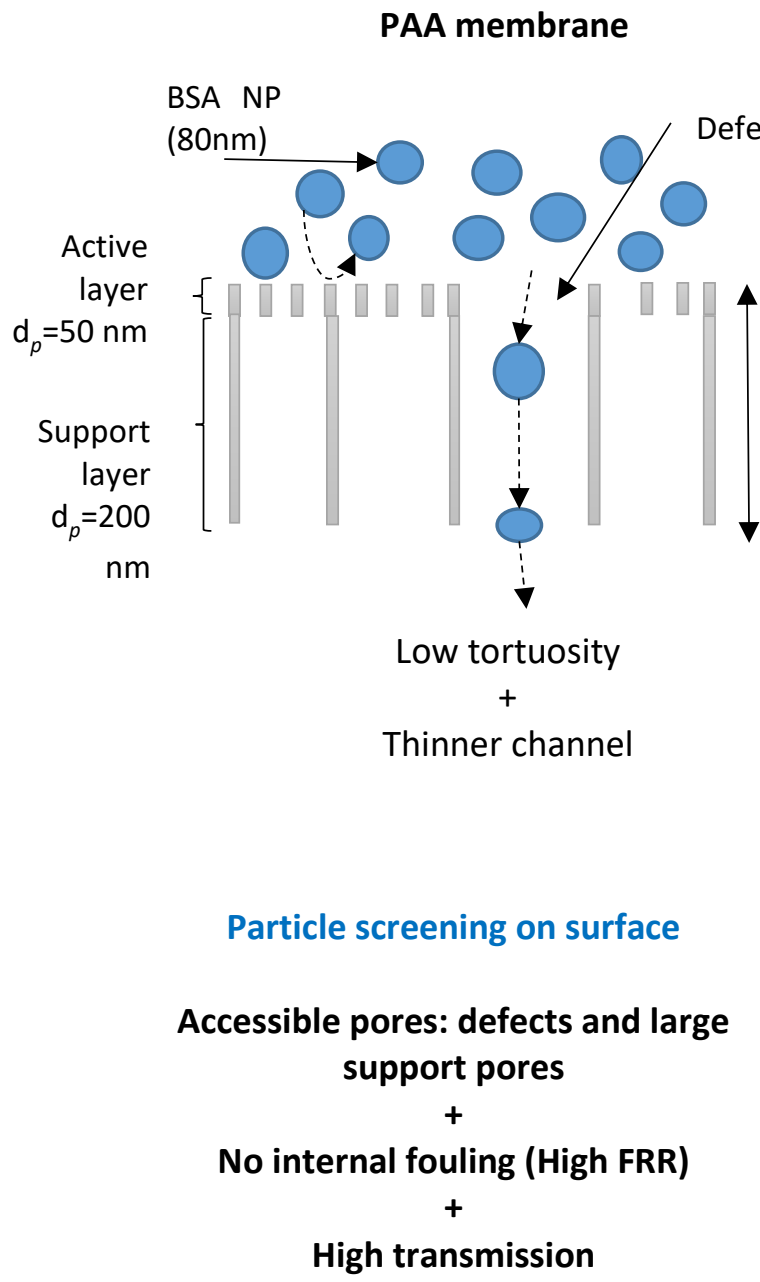


Application of the PAA membranes in the fractionation of virus particles and cell culture impurities will require characterisation of the separation performance of the membranes. For this purpose, a binary mixture of TG and BSA NP, the model solutes for viral particles with BSA were filtered through membranes with BSA used as the model impurity. The comparison showed no differences in the average flux and value of FRR \% when compared to the single solute filtrations of fouling solutes (TG and BSA NP) suggesting no further interaction of BSA and the large solutes in the internal fouling of the membrane.

\begin{tabular}{|c|c|c|c|}
\hline \multirow[t]{3}{*}{ Feed } & \multirow[t]{3}{*}{ Solutes } & \multicolumn{2}{|c|}{$\begin{array}{l}\text { Observed sieving coefficients, } \\
\text { Sobs }\end{array}$} \\
\hline & & $20 \mathrm{~nm}$ & $300 \mathrm{kDa}$ \\
\hline & & PAA & PES \\
\hline \multirow[t]{3}{*}{ Single solute } & BSA & $0.96 \pm 0.03$ & $0.96 \pm 0.02$ \\
\hline & $\mathrm{TG}$ & $0.60 \pm 0.04$ & $0.21 \pm 0.08$ \\
\hline & BSA NP & $0.03 \pm 0.01$ & $0.01 \pm 0.00$ \\
\hline Binary solutes & BSA & $0.89 \pm 0.03$ & $0.76 \pm 0.01$ \\
\hline$B S A+T G$ & TG & $0.67 \pm 0.09$ & $0.43 \pm 0.03$ \\
\hline Binary solutes & BSA & $0.68 \pm 0.03$ & $0.54 \pm 0.06$ \\
\hline BSA + BSA NP & BSA NP & $0.18 \pm 0.03$ & $0.00 \pm 0.00$ \\
\hline
\end{tabular}

Table 2 Transmission of model solutes in single solute filtrations compared to transmissions observed in filtrations of binary solute mixtures (BSA with TG or BSA NP). Data represents average values \pm one standard deviation for triplicate filtration runs.

Transmission of the respective solutes during filtration of single solute and binary solutes feed are compared as shown in Table 2. For the PAA membrane, the transmission of TG did not change significantly for the filtration of the binary solute mixture and single solute solution. BSA NP showed unusually high transmission through the PAA membrane in the binary solute feed. For PES membranes, TG transmission was almost two times higher for the binary solute feed compared to the single solute feed. This could be due to the high variability in the hydraulic permeability of the membrane discs of PES membrane even when same membrane lot was used. The membrane discs used for BSA+TG filtration had a hydraulic permeability of $1930 \pm 120 \mathrm{LMH} /$ bar compared to $1600 \pm$ $540 \mathrm{LMH} /$ bar used for the filtration of TG alone. Transmission of BSA NP in the PES membranes however remained unaffected by presence of BSA in the feed. Transmission of BSA was however affected by the fouling by larger solutes as a lower sieving coefficient of BSA was observed during filtration of binary solute mixtures as shown in table 2. Unusually high transmission of BSA NP in binary feed filtration through PAA membranes could not be explained as the same lot of the membrane was used for single, and binary mixture filtrations along with same nanoparticle batch were used. Nonetheless, it was clear from this experiment that transmission of smaller solutes such as BSA is significantly reduced in the presence of large fouling solutes resulting in lower selectivity that 
indicated by filtrations of the single solute feeds. As both membranes showed high retention of the protein nanoparticles, membranes could be used for fractionation of the binary mixtures of large protein nanoparticles and a smaller impurity such as BSA. Fractionation was however incomplete in this experiment where mixtures were filtered through membranes or feed was concentrated.

To increase the fractionation, a filtration strategy involving multiple passes of feed or diafiltration could be used. This diafiltration based fractionation process was carried out to study separation performance and filterability of the mixtures of BSA nanoparticles and BSA through PAA and PES membranes including the effect on the internal fouling of the membrane upon a lengthy process as would be encountered in actual processing conditions.

\subsection{Fractionation of mixtures of model protein solutes (BSA NP and BSA) using discontinuous diafiltration}

Discontinuous diafiltration was used to improve the fractionation of mixtures of BSA nanoparticles and BSA. Discontinuous or sequential diafiltration was used after an initial concentration step concentrating the protein mixture to 4 -fold volumetrically. A total of 12 diafiltration steps (including 2fold dilution of retentate followed by 2-fold concentration) were carried out resulting in a total of 12 diavolumes of the buffer exchanged. Final retentate solution was analysed using size exclusion chromatography.

$$
\text { Purification factor, PF }=\frac{\text { Yield (BSA NP) }}{\text { Yield (BSA monomer) }}
$$

Fig. 11 shows the fractionation experiment in discontinuous diafiltration mode and the flux decline observed. PAA membranes showed significantly higher filtrate flux throughout the filtration run with cumulative filtrate flux value of $\sim 97 \mathrm{LMH}$ compared to $\sim 70 \mathrm{LMH}$ for both PES membranes. This resulted in shorter process time of $\sim 70$ minutes for 12 diavolumes diafiltration in PAA membranes compared to $\sim 90$ minutes for the polymeric membranes. Note that both PES membrane ratings showed similar flux despite different hydraulic permeability suggesting higher fouling in the 500kDa membrane as hydraulic permeability of the $500 \mathrm{kDa}$ membrane is approximately two times higher than that of $300 \mathrm{kDa}$ PES or $20 \mathrm{~nm}$ PAA membrane.

PAA membranes showed three times higher purification factor compared to both polymeric membranes. This is due to high BSA NP retention, and low residual BSA detected in the retentates as shown in chromatograms of Fig. 12 and tabulated in Table 3. The 300kDa PES membrane retained almost all of the nanoparticles, but also had high residual BSA in the retentate. There appears to be a trade-off between the purification factor and BSA NP yield for the membranes studied. In the realworld biologics purification processes, purification factor of 780 as observed for the $300 \mathrm{kDa}$ PES membrane may be sufficient given that it also results in highest recovery of BSA NP. However, the choice of a membrane for fractionation may also be governed by other factors such as absolute impurity levels, net impurity exposure to patient depending upon the dosage and process optimisation factors (diavolumes required and membrane fouling). Limited fouling was observed for PAA 
membranes as FRR of $96 \%$ was measured after protein filtration. Fouling was more significant in the PES membranes as only 33 , and $14 \%$ of the initial buffer flux could be recovered for 300 and $500 \mathrm{kDa}$ ratings respectively. The diafiltration step also appears to result in increased fouling in the PES membrane as compared to the initial concentration step. This is evident from the reduction in the FRR $\%$ from $~ 50 \%$ (as shown in Fig. 9) to $33 \%$ for BSA NP and BSA mixture. Both PES membranes required additional chemical treatment for removal of the internal fouling and restoration of membrane permeability details of which are available in the Fig. E.1 in the appendix section.
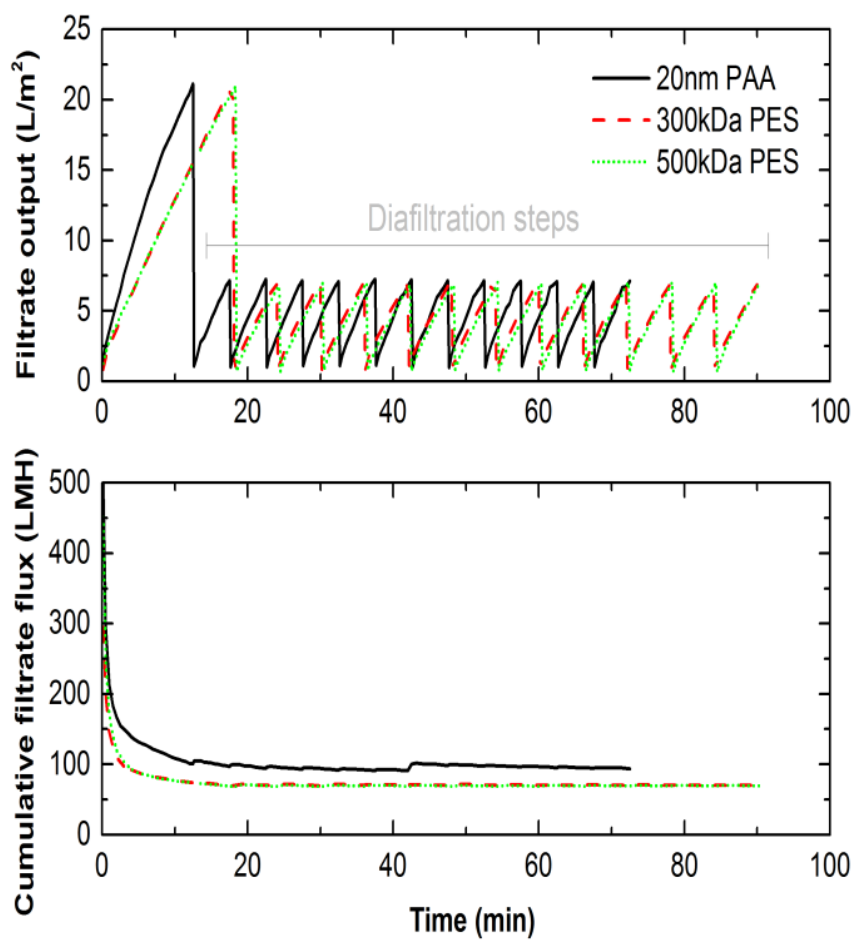

Fig. 11 Fractionation of mixture of BSA and BSA NP using $20 \mathrm{~nm}$ rated PAA, 300 and $500 \mathrm{kDa}$ PES membranes. The top chart shows the initial concentration step (filtrate output to $20 \mathrm{~L} / \mathrm{m}^{2}$ during initial 20 minutes) and discontinuous diafiltration mode used for fractionations, and the bottom chart shows cumulative filtrate flux during the initial concentration and subsequent diafiltration phase. Initial membrane loadings for all the membranes were equal and similar diafiltration strategy (diavolumes per step and total diavolumes) was used.

\begin{tabular}{llllll}
\hline Membrane & $\begin{array}{l}\% \text { BSA } \\
\text { removal } \\
\text { (permeate) }\end{array}$ & $\begin{array}{l}\text { \% BSA } \\
\text { retention }\end{array}$ & $\begin{array}{l}\text { \% residual } \\
\text { BSA } \\
\text { (retentate) }\end{array}$ & $\begin{array}{l}\text { Purification } \\
\text { Factor (BSA }\end{array}$ & $\begin{array}{l}\text { FRR } \\
(\%)\end{array}$ \\
\hline 20nm PAA & $95 \pm 3$ & $86 \pm 6$ & $0.04 \pm 0.00$ & $2170 \pm 200$ & 96 \\
\hline 300kDa PES & $92 \pm 3$ & $100 \pm 7$ & $0.13 \pm 0.01$ & $780 \pm 80$ & 33 \\
\hline 500kDa PES & $93 \pm 3$ & $82 \pm 6$ & $0.10 \pm 0.00$ & $990 \pm 100$ & 14
\end{tabular}


Table 3 Performance of different membranes for complete fractionation of mixtures of BSA NP and BSA. Data represents average values \pm one standard deviation for triplicate measurements.

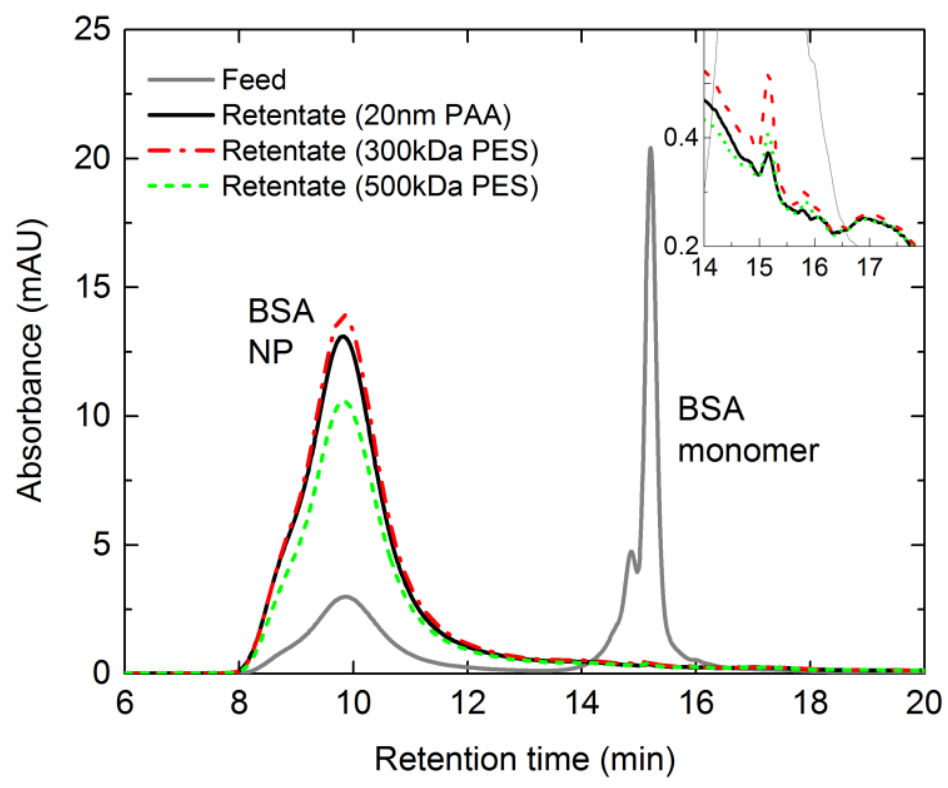

Fig. 12 High performance-size exclusion chromatograms for initial feed (BSA NP + BSA) and retentate obtained after 12 diavolumes of diafiltration performed using different membranes (20nm PAA, 300 and 500kDa rated PES membranes). Figure in the inset shows the peak of residual BSA monomer in the retentate solutions. Volume concentration factor for retentate is $\sim 4$ in relation to the feed volume. Chromatograms were obtained using BioSEC-5 column (7.8 $\times 300 \mathrm{~mm}$ ) at a flow rate of $0.8 \mathrm{ml} / \mathrm{min}$ with PBS as elution buffer and diode array detector for measurement of absorbance by proteins at a wavelength of $280 \mathrm{~nm}$.

\section{Conclusions}

To the best of our knowledge, this was the first study comparing conventional polymeric membranes with the porous anodic alumina under the same filtration conditions. Previous studies by Prádanos et al. [19, 20] and Lee et. al. [18] have studied PAA membranes with proteins but did not offer any comparison with traditionally used polymeric membranes. A significant challenge in such a comparison was the different rating standards used for PAA and polymeric ultrafiltration membranes. Therefore membranes were first experimentally matched on the basis of hydraulic permeability and dextran sieving characteristics. This was performed for a $20 \mathrm{~nm}$ rated PAA membrane and compared to three ratings of PES membranes. It was found a $300 \mathrm{kDa}$ rated PES membrane matched most closely. Interestingly, the dextran sieving curve for the PAA membrane was sharper than that of the PES membranes highlighting the narrow pore size distribution of these membranes.

Using the matched PAA, PES membranes an experimental design was chosen to characterise the filtration and separation performance of the two membrane types for viral vector purification. This characterisation was done using large solutes like thyroglobulin ( 22 nm hydrodynamic diameter) and 
BSA nanoparticles ( $80 \mathrm{~nm}$ diameter) as mimics of common viral vectors such as AAVs and AdVs respectively. PAA membranes exhibited 3-4 fold higher transmissions of these mimics as well as 2-3 fold higher fouling resistance in comparison to the PES membrane. Both membranes are unsuitable

571 for ultrafiltration of smaller viruses such as AAVs as the mimic solute thyroglobulin was only partially

572 retained and significantly fouled both of the membranes. For BSA nanoparticles (the AdV mimic), both

573 membranes are highly retentive, and PAA membranes show remarkably high restoration of

574 permeability above $90 \%$ of the initial value compared to $50 \%$ for PES membranes upon rinsing the membrane and stirred cell surfaces with the buffer solution. PAA membranes also exhibited robust separation performance for a complete fractionation of a binary mixture of BSA and BSA nanoparticles in an extended diafiltration process. PAA membranes showed $30 \%$ higher flux and 3 fold higher purification factor for BSA nanoparticles in comparison to the PES membrane and more than $90 \%$ of permeability restored while the PES membrane fouled much more extensively with only $33 \%$ of the permeability restored which necessitated a chemical cleaning.

We propose that the observed differences in the filtration and separation performance of the two membranes are a result of significant differences in their architecture giving rise to different screening mechanisms. PAA membranes screen large solutes like BSA nanoparticles above membrane surface due to a smaller and narrow pore size distribution resulting in very low fouling. PES membranes on the other hand allow such solutes to enter the membrane through the larger pores of the wider pore size distribution typical of this membrane type, but eventually trap these particles within the tortuous pore channels of the thicker PES membrane resulting in higher internal fouling. Leaky transmission of solutes seen in the PAA membranes is likely due to some defects on the active layer allowing access to the highly permeable straight pore channels of the support layer. Low fouling and high nanoparticle retention make PAA membranes an attractive candidate for ultrafiltration of sensitive biomolecules such as viral vectors by reducing process time by reducing the requirement of chemical cleaning in between batches.

To further the development of PAA membranes for virus ultrafiltration, fabrication of defect-free membranes should be studied to reduce their susceptibility to loss of performance due to these defects. To substantiate the proposed screening mechanisms of the two membrane types, direct observation of the location of the fouling in the membrane bed could be performed using fluorescently tagged solutes and confocal laser scanning microscopy. Another extension of the present work would be to use a real viral feed and cross flow conditions to leverage high mass transfer characteristics of this mode of operation with representative feed materials. The brittle and fragile nature of PAA membranes may pose a challenge to their adoption at industrial scale so alternative membrane materials with similar membrane architecture should be considered. One such alternative is selfassembled block copolymer membranes. studies and the department of biochemical engineering for research funding and facility support. 
607 Appendix A. Size exclusion chromatogram of BSA solution used in filtration experiment

608 showing high molecular weight (HMW) components

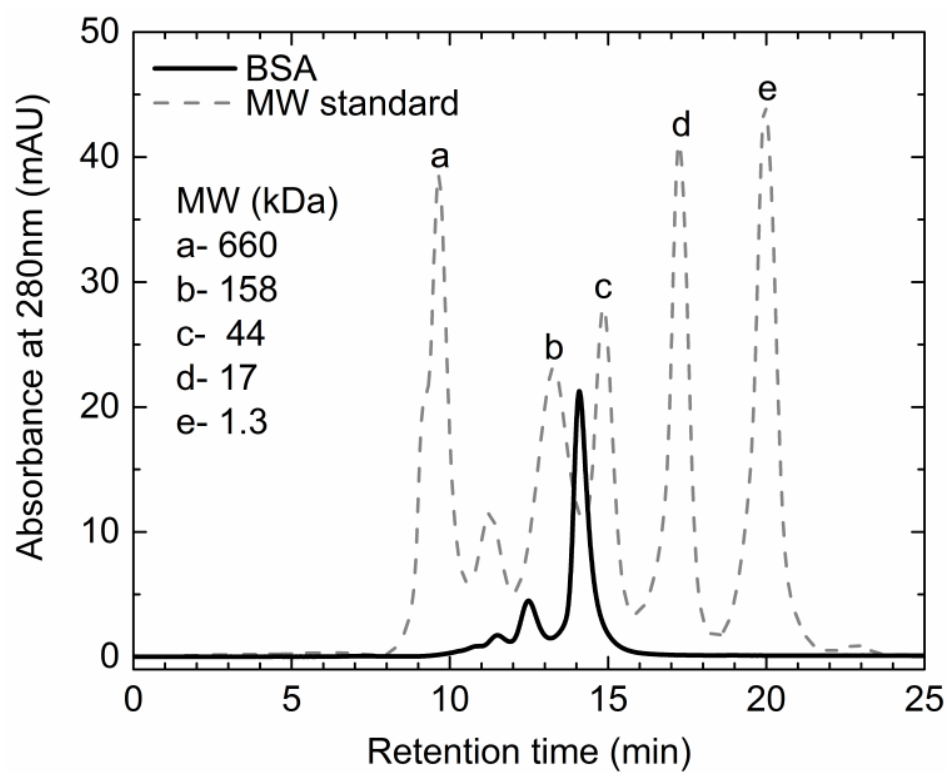

609

Fig. A.1 Chromatogram overlay of the molecular weight (MW) standard (dashed line) and the BSA solution (solid line) obtained using a size exclusion column, TSKgel3000SWXL at a flow rate of $0.6 \mathrm{~mL} / \mathrm{min}$ under isocratic elution with PBS (detailed method is described in section 2.5). Peak labels represent the molecular weights $(\mathrm{kDa})$ of the peak proteins in the standard. BSA monomer ( $\sim 67 \mathrm{kDa})$ corresponds to the major peak at the retention time of 14 minutes in the chromatograms. Chromatogram also shows the presence of the high molecular weight components (peaks with retention time below $14 \mathrm{~min}$ ) in the BSA solution. Relative amount of these high molecular weight components in BSA solution was estimated to be $\sim 23 \%$ from the peak area\%. 

curve-fitting of the experimental data with mathematical expressions of mechanisms of fouling

Mechanism Mathematical expression for filtrate volume, $V\left(\mathrm{~m}^{3} / \mathrm{m}^{2}\right)$

Standard blocking $\quad \mathrm{V}=\left(\frac{1}{\mathrm{~J}_{0} \mathrm{t}}+\frac{\mathrm{k}_{\mathrm{s}}}{2}\right)^{-1}$

Complete blocking $\quad \mathrm{V}=\frac{\mathrm{J}_{\mathrm{o}}}{\mathrm{k}_{\mathrm{b}}}\left(1-\exp \left(-\mathrm{k}_{\mathrm{b}} \mathrm{t}\right)\right)$

Intermediate blocking $\quad \mathrm{V}=\frac{1}{\mathrm{k}_{\mathrm{i}}} \ln \left(1+\mathrm{k}_{\mathrm{i}} \mathrm{J}_{\mathrm{o}} \mathrm{t}\right)$

Cake filtration

$$
\mathrm{V}=\frac{1}{\mathrm{k}_{\mathrm{c}} \mathrm{J}_{\mathrm{o}}}\left(\sqrt{\left(1+2 \mathrm{k}_{\mathrm{c}} \mathrm{J}_{\mathrm{o}}^{2} \mathrm{t}\right)}-1\right)
$$

621 Table B.1 Mathematical expressions of the fundamental mechanisms of fouling in constant

622 pressure filtrations as described by Bolton et al. [27] and used in this study.

623 A mechanism is identified to be dominant mechanism by fitting these expressions to the experimental

624 filtration data (volume filtered per unit membrane area, $\mathrm{V}\left(\mathrm{m}^{3} / \mathrm{m}^{2}\right)$; time, $\mathrm{t}(\mathrm{sec})$ and initial buffer flux, $\mathrm{J}_{\mathrm{o}}$,

$625(\mathrm{~m} / \mathrm{s})) . \mathrm{k}_{\mathrm{x}}$ represents fouling constants for respective models with different units for different

626 mechanisms. 
Results of curve fitting of the filtration data with mathematical models of fouling

\begin{tabular}{|c|c|c|c|c|c|c|c|}
\hline & Fouling & BS & lanop & ticles & & hyrog & bulin \\
\hline & & $\begin{array}{l}\text { SSR } \\
\left(\times 10^{-3}\right)\end{array}$ & $\mathbf{R}^{2}$ & Parameter & $\begin{array}{l}\text { SSR } \\
\left(\times 10^{-4}\right)\end{array}$ & $\mathbf{R}^{2}$ & Parameter \\
\hline & Standard & $1.24 \pm 0.06$ & 0.49 & $\mathrm{k}_{\mathrm{s}}=137 \pm 1$ & $0.07 \pm 0.04$ & 0.99 & $\mathrm{k}_{\mathrm{s}}=78 \pm 2$ \\
\hline$\frac{\mathrm{d}}{\alpha}$ & Complete & $1.78 \pm 0.78$ & 0.27 & $\mathrm{k}_{\mathrm{b}}=0.03$ & $0.30 \pm 0.11$ & 0.95 & $\mathrm{k}_{\mathrm{b}}=0.02$ \\
\hline స్ & $\begin{array}{l}\text { Intermediat } \\
\text { e }\end{array}$ & $0.65 \pm 0.02$ & 0.73 & $\mathrm{k}_{\mathrm{i}}=278 \pm 5$ & $0.02 \pm 0.00$ & 1.00 & $\mathrm{k}_{\mathrm{i}}=112 \pm 4$ \\
\hline & Cake & $0.13+0.00$ & 094 & $\mathrm{k}_{\mathrm{c}}\left(\mathrm{x} 10^{-6}\right)$ & $015+003$ & 098 & $\mathrm{k}_{\mathrm{c}}\left(\mathrm{x} 10^{-6}\right)$ \\
\hline & & $0.10 \pm 0.00$ & 0.94 & $=4.4 \pm 0.2$ & $0.15 \pm 0.00$ & 0.00 & $=0.64 \pm 0.1$ \\
\hline & & $\begin{array}{l}\text { SSR } \\
\left(\times 10^{-3}\right)\end{array}$ & $\mathbf{R}^{2}$ & Parameter & $\begin{array}{l}\text { SSR } \\
\left(\times 10^{-3}\right)\end{array}$ & $\mathbf{R}^{2}$ & Parameter \\
\hline & Standard & $1.83 \pm 0.14$ & 0.40 & $\mathrm{k}_{\mathrm{s}}=145 \pm 1$ & $0.17 \pm 0.05$ & 0.85 & $\mathrm{k}_{\mathrm{s}}=100 \pm 7$ \\
\hline 㟧 & Complete & $2.45 \pm 0.16$ & 0.20 & $\mathrm{k}_{\mathrm{b}}=0.03$ & $0.33 \pm 0.07$ & 0.71 & $\mathrm{~kb}=0.02$ \\
\hline 옹 & $\begin{array}{l}\text { Intermediat } \\
\text { e }\end{array}$ & $0.95 \pm 0.08$ & 0.70 & $\mathrm{k}_{\mathrm{i}}=321 \pm 4$ & $0.08 \pm 0.03$ & 0.94 & $\mathrm{k}_{\mathrm{i}}=160 \pm 20$ \\
\hline & Cake & $0.17 \pm 0.02$ & 0.94 & $\begin{array}{l}\mathrm{k}_{\mathrm{c}}\left(\times 10^{-6}\right) \\
=5.8 \pm 0.3\end{array}$ & $0.01 \pm 0.01$ & 0.99 & 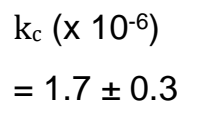 \\
\hline
\end{tabular}

628 Table B.2 Results of the curve fitting of experimental filtration data (model solute filtration

629 through PAA and PES membrane) with well-established mathematical models of the

630 fundamental mechanisms of fouling.

631 Curve fitting was carried out using least-square algorithm in software, OriginPro 9.0 (OriginLab

632 Corp.,USA). Parameters represent kinetic constants of the respective mechanisms, $\mathrm{k}_{\mathrm{s}}\left(\mathrm{m}^{-1}\right), \mathrm{k}_{\mathrm{b}}\left(\mathrm{s}^{-1}\right), \mathrm{k}_{\mathrm{i}}$ $633\left(\mathrm{~m}^{-1}\right)$ and $\mathrm{k}_{\mathrm{c}}\left(\mathrm{sm}^{-2} \times 10^{-6}\right)$. Regression coefficient $\left(\mathrm{R}^{2}\right)$ and sum of square of the residuals (SSR) signify 634 the goodness of the fits. Standard error values for all kinetic constants were less than $5 \%$ of the value 635 of the kinetic constants. Data is represented as average values \pm one standard deviation for triplicate 636 filtration runs. 
A

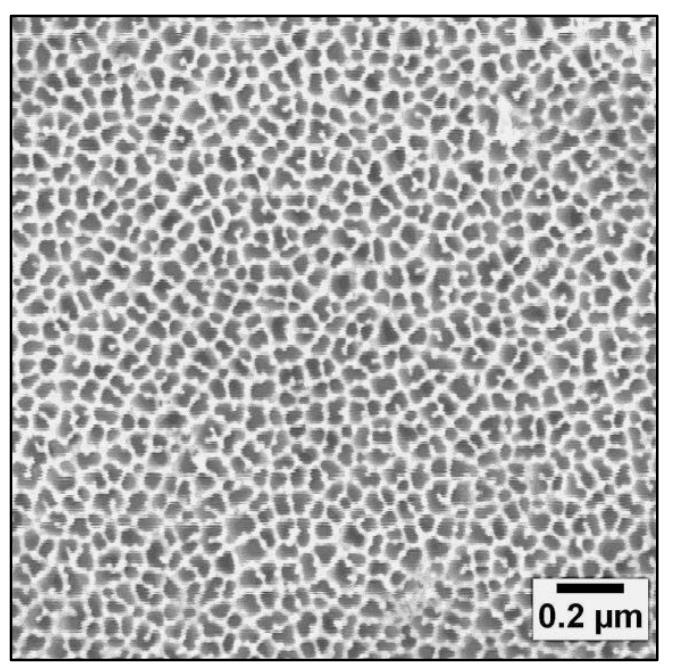

C

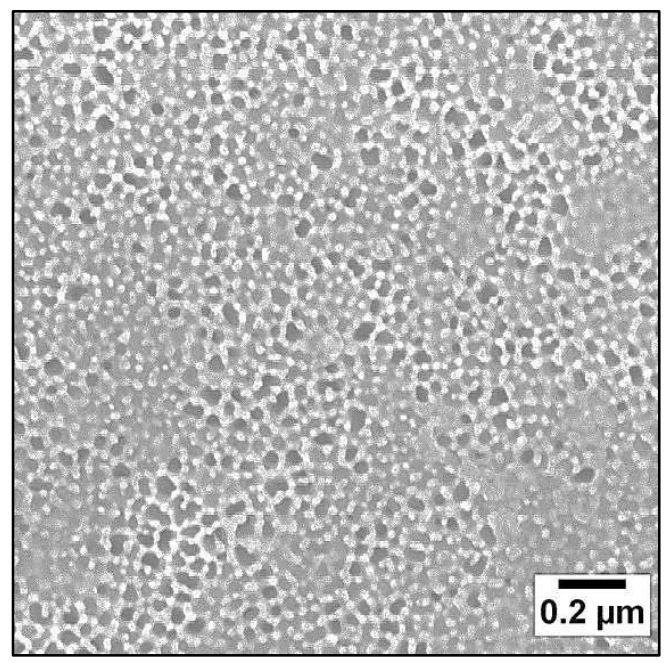

B

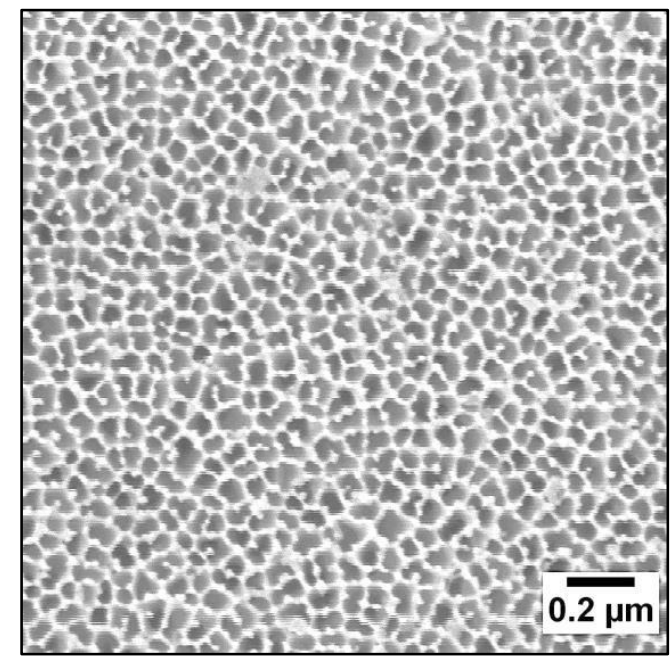

D

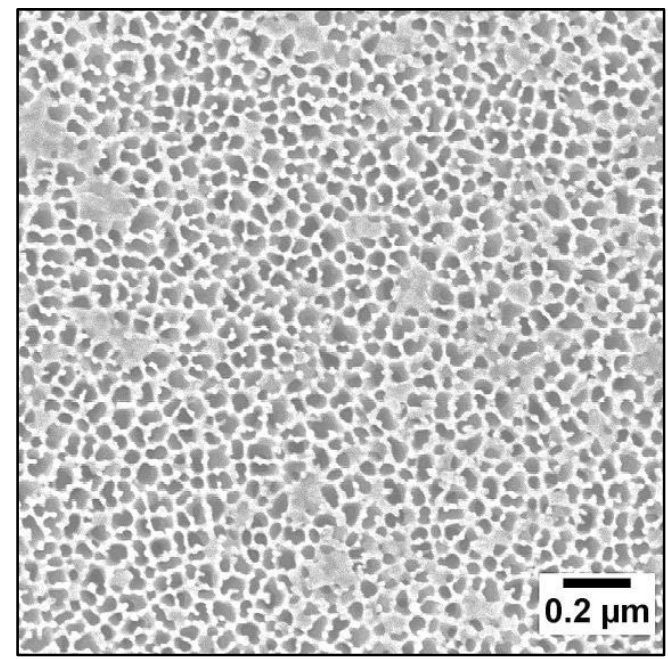

639

640

641

642

643

644

645

646

647

Fig. C.1 SEM images showing fouling by different model solutes on the active layer surface of 20nm rated PAA membranes. A- Unused membrane, B- BSA fouled, C- TG fouled and D- BSA nanoparticles fouled membrane.

Scale bar represents $0.2 \mu \mathrm{m}$ and images were taken at a magnification of 100,000 for all of the samples. Images were obtained after drying and coating the membranes with uniform ultrathin $(<1$ $\mathrm{nm}$ ) layer of platinum using sputter coater and analysed using InLens detector with less than $5 \mathrm{kV}$ gun voltage. Field emission scanning electron microscope (Gemini Sigma, Carl Zeiss AG, Germany) was used. 
A
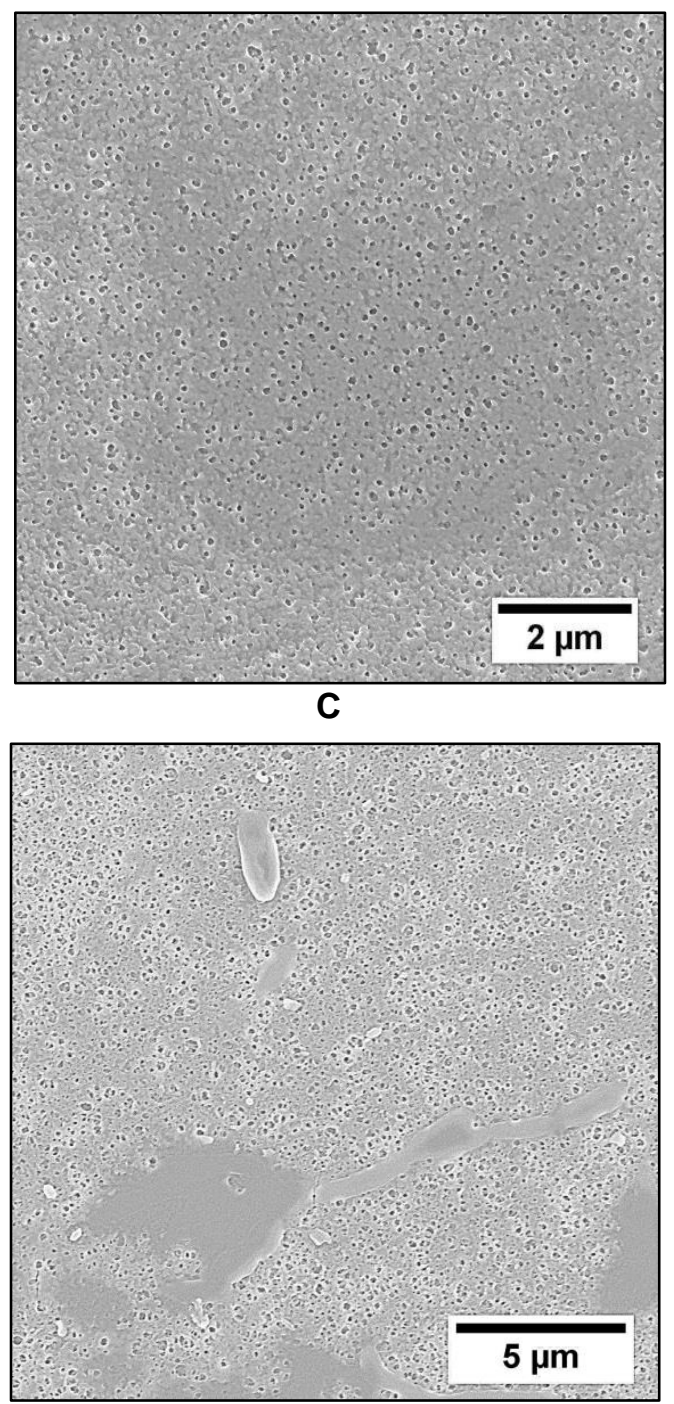

B
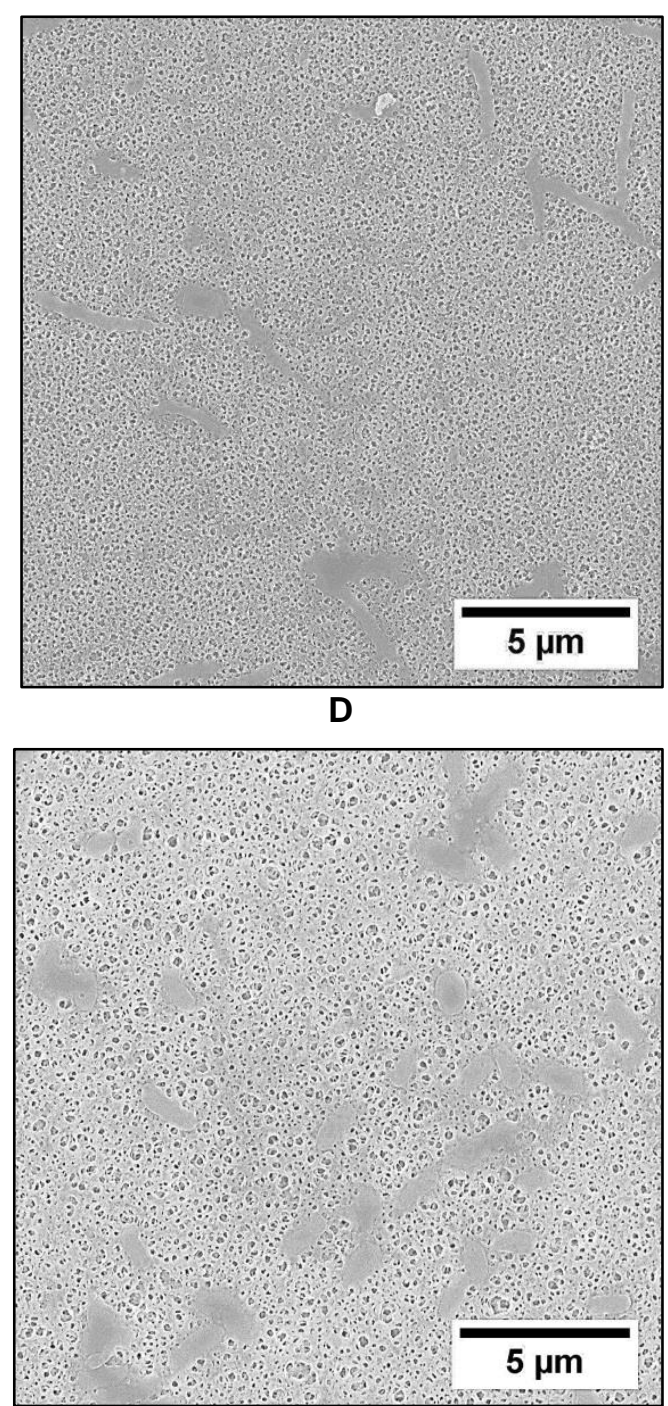

Fig. D.1 SEM images showing fouling by different model solutes on the active layer surface of 300kDa PES membranes. A- Unused membrane, B- BSA fouled, C- TG fouled and D- BSA nanoparticles fouled membrane.

654 Scale bar represents $5 \mu \mathrm{m}$ (except A) and images were taken at a magnification of 10,000 (except 65520,000 for A) for all of the samples. Images were obtained after drying the membranes and coating 656 with ultrathin $(<1 \mathrm{~nm})$ and uniform layer of platinum using sputters coater and analysed using InLens 657 detector with less than $5 \mathrm{kV}$ gun voltage. Field emission scanning electron microscope (Gemini Sigma, 658 Carl Zeiss AG, Germany) was used. 
Appendix E. Effect of various treatments on flux recovery ratio (\% of clean membrane flux) of fouled membranes after 12 diavolumes diafiltration process for fractionation of BSA and BSA NP

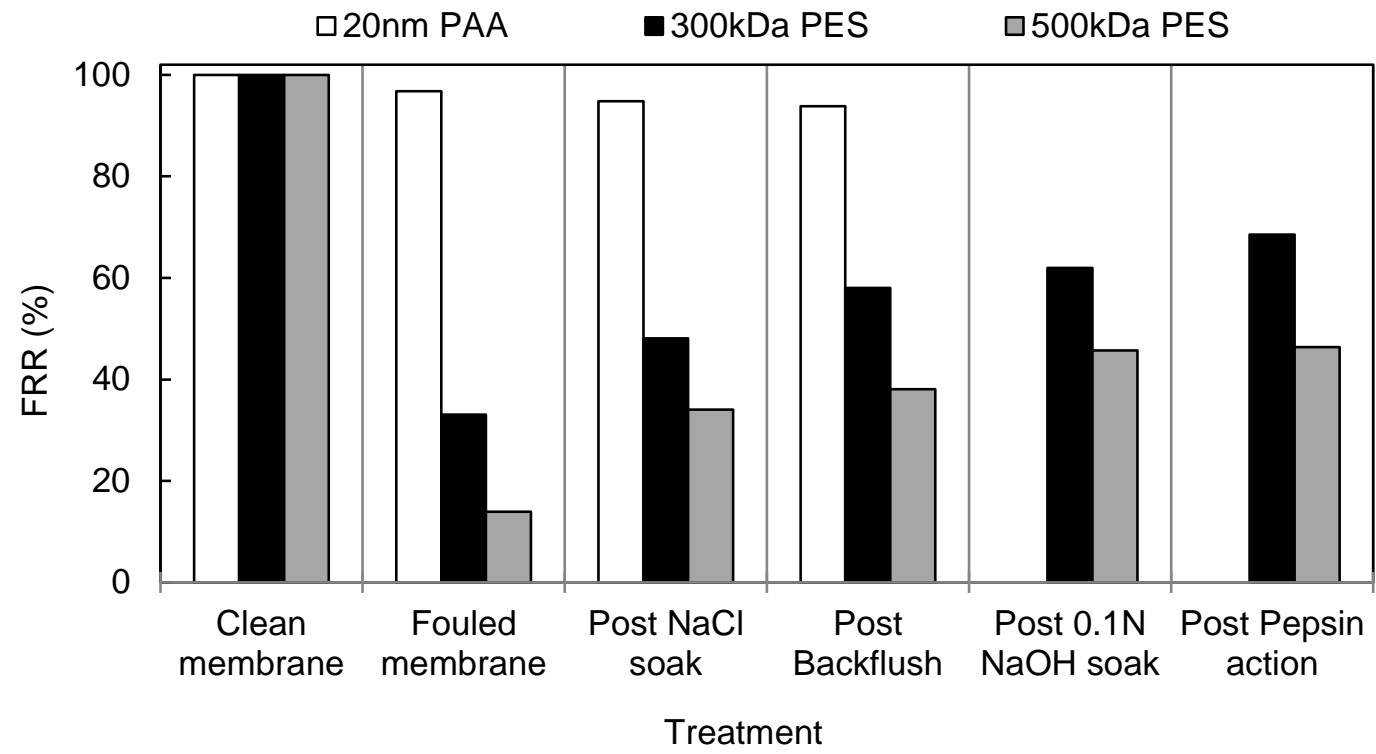

Fig. E.1 Flux recovery ratio, FRR (\% of membrane permeability for fresh membranes) for PAA membrane and PES membranes after an extended UF/DF experiment (12 DF cycles each of one diavolume) for fractionation of a mixture of BSA and BSA NP and effect of various chemical treatments to remove fouling.

Membranes were treated (in sequence) with $1 \mathrm{M} \mathrm{NaCl}$ soak for 24 hours; buffer backflush ( $2 \times \mathrm{TMP}$ used in protein filtration), $0.1 \mathrm{~N} \mathrm{NaOH}$ soak for an hour and proteolytic enzyme treatment for 18 hours at room temperature). PAA membrane showed $\sim 96 \%$ of initial buffer flux recovered after rinsing with buffer. Polymeric membranes could not be restored to similar levels even with the chemical treatments. 

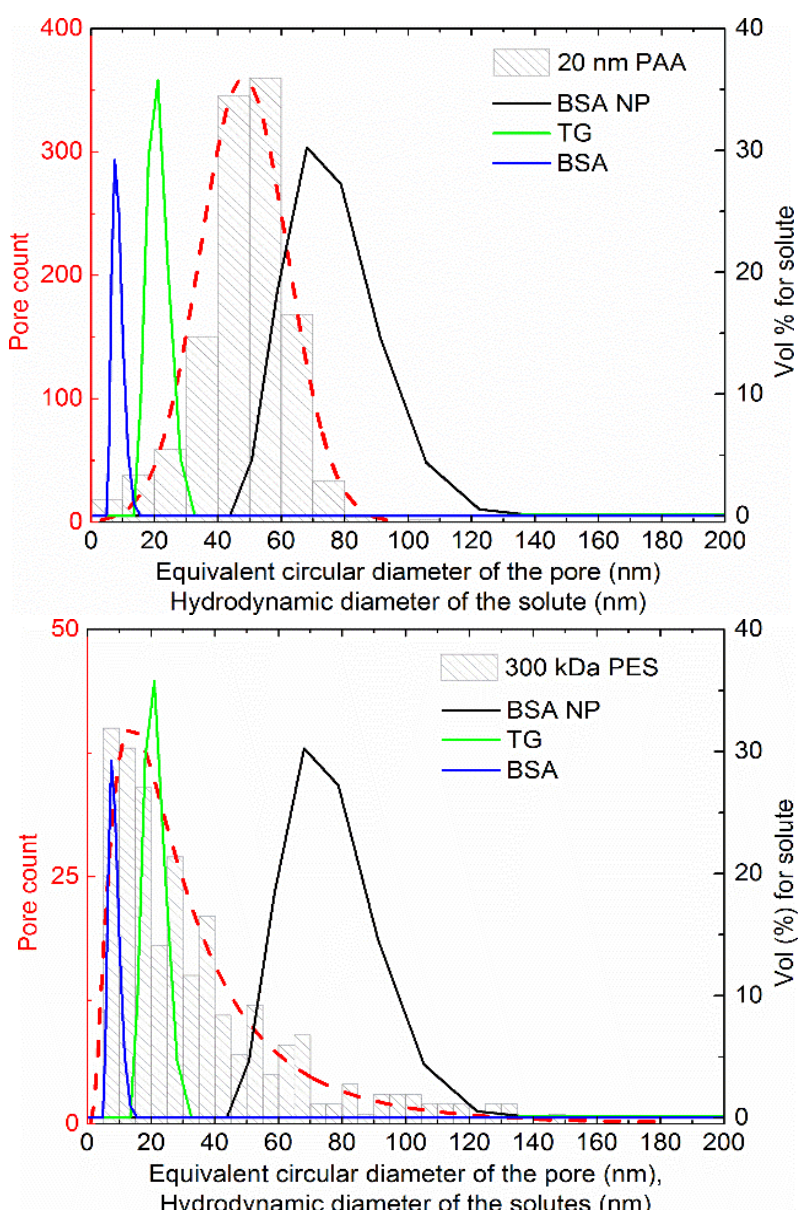

675 Fig. F.1 Pore size distribution of membrane surface for 20nm PAA and 300kDa PES membrane 676 overlaid with particle size distribution of various solutes.

677 The grey bars and red dotted line represent the histogram of pore counted (Left Y-axis) upon 678 SEM image analysis and fitting of distribution curve respectively for membranes. Particle size 679 distribution of BSA NP, TG and BSA are displayed as solid lines with right side $Y$ axis.

680 Surface pore size in $20 \mathrm{~nm}$ PAA and 300kDa PES membranes followed normal and log-normal 681 distribution respectively. Larger pore sizes (>90 nm to $180 \mathrm{~nm}$ ) were observed for the 300kDa PES 682 membrane. 
684 [1] E.I. Trilisky, A.M. Lenhoff, Sorption processes in ion-exchange chromatography of viruses, J. 685 Chromatogr. A, 1142 (2007) 2-12.

686 [2] M. Yu, Y. Li, S. Zhang, X. Li, Y. Yang, Y. Chen, G. Ma, Z. Su, Improving stability of virus-like particles by ion-exchange chromatographic supports with large pore size: Advantages of gigaporous media beyond enhanced binding capacity, J. Chromatogr. A, 1331 (2014) 69-79.

[3] C.S. Fernandes, B. Goncalves, M. Sousa, D.L. Martins, T. Barroso, A.S. Pina, C. Peixoto, A. Aguiar-Ricardo, A.C. Roque, Biobased monoliths for adenovirus purification, ACS Appl. Mater. Interfaces, 7 (2015) 6605-6612.

[4] Y. Wu, D. Abraham, G. Carta, Comparison of perfusion media and monoliths for protein and viruslike particle chromatography, J. Chromatogr. A, 1447 (2016) 72-81.

[5] O. Hardick, S. Dods, B. Stevens, D.G. Bracewell, Nanofiber adsorbents for high productivity downstream processing, Biotechnol. Bioeng., 110 (2013) 1119-1128.

[6] P. Nestola, D.L. Martins, C. Peixoto, S. Roederstein, T. Schleuss, P.M. Alves, J.P.B. Mota, M.J.T. Carrondo, Evaluation of novel large cut-off ultrafiltration membranes for adenovirus serotype 5 (Ad5) concentration, PLoS ONE, 9 (2014) 22.

[7] M. Weggeman, Viurs purification using ultrafiltration, in: USPTO (Ed.), Crucell Holland B.V., Leiden (NL), 2013, pp. 34.

[8] C. Peixoto, T.B. Ferreira, M.F. Sousa, M.J. Carrondo, P.M. Alves, Towards purification of adenoviral vectors based on membrane technology, Biotechnol. Prog., 24 (2008) 1290-1296.

[9] S. Subramanian, G.M. Altaras, J. Chen, B.S. Hughes, W. Zhou, N.E. Altaras, Pilot-scale adenovirus seed production through concurrent virus release and concentration by hollow fiber filtration, Biotechnol. Prog., 21 (2005) 851-859.

[10] T. Urase, K. Yamamoto, S. Ohgaki, Effect of pore structure of membranes and module configuration on virus retention, J. Membr. Sci., 115 (1996) 21-29.

[11] S. Giglia, D. Bohonak, P. Greenhalgh, A. Leahy, Measurement of pore size distribution and prediction of membrane filter virus retention using liquid-liquid porometry, J. Membr. Sci., 476 (2015) 399-409.

[12] J.J. Deng, C.S. Toh, Impedimetric DNA Biosensor Based on a Nanoporous Alumina Membrane for the Detection of the Specific Oligonucleotide Sequence of Dengue Virus, Sensors, 13 (2013) 7774-7785.

[13] C.C. Chen, Z.L. Lai, G.J. Wang, C.Y. Wu, Polymerase chain reaction-free detection of hepatitis B virus DNA using a nanostructured impedance biosensor, Biosens Bioelectron, 77 (2016) 603-608. [14] P. Chaturvedi, S.D. Rodriguez, I. Vlassiouk, I.A. Hansen, S.N. Smirnov, Simple and Versatile Detection of Viruses Using Anodized Alumina Membranes, ACS Sens, 1 (2016) 488-492.

[15] A.C. Attaluri, Z. Huang, A. Belwalkar, W. Van Geertruyden, D. Gao, W. Misiolek, Evaluation of nano-porous alumina membranes for hemodialysis application, ASAIO J, 55 (2009) 217-223.

[16] H.U. Osmanbeyoglu, T.B. Hur, H.K. Kim, Thin alumina nanoporous membranes for similar size biomolecule separation, J. Membr. Sci., 343 (2009) 1-6.

[17] T. Yamashita, S. Kodama, T. Kemmei, M. Ohto, E. Nakayama, T. Muramoto, A. Yamaguchi, N. Teramae, N. Takayanagi, Separation of adenine, adenosine-5'-monophosphate and adenosine-5'triphosphate by fluidic chip with nanometre-order diameter columns inside porous anodic alumina using an aqueous mobile phase, Lab Chip, 9 (2009) 1337-1339.

[18] K.P. Lee, D. Mattia, Monolithic nanoporous alumina membranes for ultrafiltration applications: Characterization, selectivity-permeability analysis and fouling studies, J. Membr. Sci., 435 (2013) 5261.

[19] P. Prádanos, A. Hernández, J.I. Calvo, F. Tejerina, Mechanisms of protein fouling in cross-flow UF through an asymmetric inorganic membrane, J. Membr. Sci., 114 (1996) 115-126.

[20] P. Pradanos, J.I. Arribas, A. Hernandez, Retention of Proteins in Cross-Flow Uf through Asymmetric Inorganic Membranes, AIChE J., 40 (1994) 1901-1910.

[21] J.M. Moon, D. Akin, Y. Xuan, P.D. Ye, P.X. Guo, R. Bashir, Capture and alignment of phi29 viral particles in sub-40 nanometer porous alumina membranes, Biomed. Microdevices, 11 (2009) 135142.

[22] G. Jeon, M. Jee, S.Y. Yang, B.Y. Lee, S.K. Jang, J.K. Kim, Hierarchically Self-Organized Monolithic Nanoporous Membrane for Excellent Virus Enrichment, ACS Appl. Mater. Interfaces, 6 (2014) 1200-1206.

[23] G.M.F. Braas, S.G. Walker, A. Lyddiatt, Recovery in aqueous two-phase systems of nanoparticulates applied as surrogate mimics for viral gene therapy vectors, J. Chromatogr. B, 743 (2000) 409-419. 
[24] S. Joseph, L. Wenger, D. Bracewell, O. Thomas, Manufacture and characterisation of protein nanoparticles as surrogate virus and VLP mimetics for the optimisation of chromatography media, New Biotechnol., 33 (2016) S115.

[25] B. Storp, A. Engel, A. Boeker, M. Ploeger, K. Langer, Albumin nanoparticles with predictable size by desolvation procedure, J. Microencapsul., 29 (2012) 138-146. dimensional difference gel electrophoresis (2D-DIGE): Implications for downstream process development, Biotechnol. Bioeng., 105 (2010) 306-316. [27] G. Bolton, D. LaCasse, R. Kuriyel, Combined models of membrane fouling: Development and application to microfiltration and ultrafiltration of biological fluids, J. Membr. Sci., 277 (2006) 75-84. [28] P. Mulherkar, R. van Reis, Flex test: a fluorescent dextran test for UF membrane characterization, J. Membr. Sci., 236 (2004) 171-182.

[29] B.L. Cheang, A.L. Zydney, A two-stage ultrafiltration process for fractionation of whey protein isolate, J. Membr. Sci., 231 (2004) 159-167.

[30] E. Burova, E. Loffe, Chromatooraphic purification of recombinant adenoviral and adenoassociated viral vectors: methods and implications, Gene Therapy, 12 (2005) S5-S17.

[31] M. Bakhshayeshi, D.M. Kanani, A. Mehta, R. van Reis, R. Kuriyel, N. Jackson, A.L. Zydney, Dextran sieving test for characterization of virus filtration membranes, J. Membr. Sci., 379 (2011) 239248.

[32] A.L. Zydney, A. Xenopoulos, Improving dextran tests for ultrafiltration membranes: Effect of device format, J. Membr. Sci., 291 (2007) 180-190.

[33] H. Lutz, Ultrafiltration for Bioprocessing, 1st ed., Woodhead Publishing, Cambridge,UK, 2015. [34] M.C. Porter, Concentration Polarization with Membrane Ultrafiltration, Ind. Eng. Chem. Prod. Res. Dev., 11 (1972) 234-248.

[35] V.G.J. Rodgers, R.E. Sparks, Effect of transmembrane pressure pulsing on concentration polarization, J. Membr. Sci., 68 (1992) 149-168.

[36] A. Tandon, S.K. Gupta, G.P. Agarwal, Modelling of protein transmission through ultrafiltration membranes, J. Membr. Sci., 97 (1994) 83-90. 